Alternativas para propagação das atualizações de um banco de dados operacional para um Data Wärehouse

Bianka Maria Moura Teixeira Gonçalves

\author{
DISSERTAÇÃO DE MESTRADO APRESENTADO AO \\ INSTITUTO DE MATEMÁTICA E ESTATÍSTICA DA \\ UNIVERSIDADE DE SÃO PAULO \\ COMO REQUISITO PARA OBTENÇÃO DO TÍTULO \\ DE MESTRE EM CIÊNCIA DA COMPUTAÇÃO
} Curso: Mestrado em Ciência da Computação Área de Concentração: Banco de Dados Orientador: Prof. Dr. João Eduardo Ferreira — São Paülo, SP - Novembro de 2002 - 


\section{Alternativas para propagação das atualizações de um banco de dados operacional para um Data Warehouse}

Este exemplar corresponde à redação final da dissertação devidamente corrigida e defendida por Bianka Maria Moura Teixeira Gonçalves e aprovada pela comissão julgadora.

São Paulo, 17 de janeiro de 2003

Banca examinadora:

Prof. Dr. João Eduardo Ferreira (orientador) (IME-USP)

Prof. Dr. Marcelo Finger (IME-USP)

Profa. Dra. Marina Teresa Pires Vieira (DC-UF SCar) 


\section{Sumário}

1 Introdução $\quad 8$

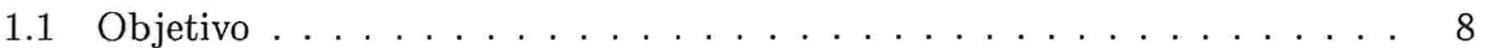

1.2 Organização deste trabalho . . . . . . . . . . . . . . 8

1.3 Introdução e caracterização do problema . . . . . . . . . . . . . 9

1.3.1 Manutenção de visão síncrona de dados . . . . . . . . . . . . . . . 11

1.3.2 Atualização de Warehouse com única fonte . . . . . . . . . . . . 12

1.3.3 Atualização de warehouse com múltiplas fontes . . . . . . . . . . 13

1.3.4 Abordagens para se prevenir a inconsistência de atualizações de dados em data warehouse . . . . . . . . . . . . . . 15

2 Algoritmos síncronos para atualizações de dados em data warehouse 17

2.1 Descrição geral dos algoritmos . . . . . . . . . . . . . . 17

2.1.1 Definições dos conceitos básicos comuns aos algoritmos . . . . . . 18

2.2 Detalhes do algoritmo de compensação ansioso

(Eager Compensation Algorithm) . . . . . . . . . . . . . . . . . . 21

2.2.1 Definições dos conceitos básicos . . . . . . . . . . . . . . . 21

2.2 .2 Descrição do Algoritmo ECA . . . . . . . . . . . . . . 23

2.2 .3 Algoritmo ECA . . . . . . . . . . . . . . . 24

2.2 .4 Exemplos . . . . . . . . . . . . . . . 25

2.3 Propriedades da família ECA . . . . . . . . . . . . 27

2.4 Família de Algoritmos Estroboscópicos (Strobe Algorithms Family) . . . . 28

2.4 .1 Definições dos conceitos básicos . . . . . . . . . . . . 28

2.4 .2 Descrição do algoritmo Strobe . . . . . . . . . . . . . . 30

2.4 .3 Algoritmo Strobe . . . . . . . . . . . . . . . . . . 31

2.4 .4 Exemplos . . . . . . . . . . . . . . . . . 32

2.5 Algoritmo Estroboscópico Completo (Complete Strobe Algorithm) . . . . . 34

2.6 Família de algoritmos de varredura (Sweep Algorithm Family) . . . . . . . 35

2.6.1 Definição dos conceitos básicos . . . . . . . . . . . . 35

2.6.2 Descrição do Algoritmo Sweep . . . . . . . . . . . . . . . . 36 
2.6.3 Módulo Atualização\&Servidor Consulta . . . . . . . . . . . . . 38

2.6 .4 Módulo data warehouse . . . . . . . . . . . . . . . . 39

2.6 .5 Exemplo . . . . . . . . . . . . . . . . 41

2.7 Algoritmo Varredura Aninhado ( Nested Sweep Algorithm) . . . . . . . . . 42

3 Algoritmos Assíncronos $\quad 45$

3.1 Algoritmo TxnWrap . . . . . . . . . . . . . . . . . . . 45

3.1.1 Anomalias de manutenção de data warehouse . . . . . . . . . . 45

3.1.2 Transação_DWMS: modelagem transacional da manutenção de data warehouse ........................ 46

3.1.3 Transações em um ambiente de data warehouse . . . . . . . . . . 47

3.1.4 Um modelo transacional : transação_SGDW . . . . . . . . . . . . . 47

3.1.5 Escalonamento de transações_SGDW . . . . . . . . . . . . . . . 48

3.1.6 Conflitos entre transações_SGDW . . . . . . . . . . . . . 48

3.1.7 Serialização das transações_SGDW . . . . . . . . . . . . . . 48

3.1.8 Algoritmo de controle de concorrência de multiVersão para transa-

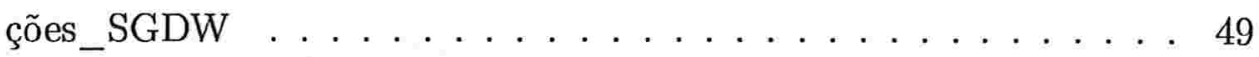

3.1 .9 Materialização dos wrappers . . . . . . . . . . . . . 50

3.1 .10 Gerenciamento de versão . . . . . . . . . . . . . . . . . . 51

3.1 .11 Criação de versão no wrapper . . . . . . . . . . . . . . . . . 51

3.1 .12 Leitura de versão no wrapper . . . . . . . . . . . . . . . . . 52

3.1 .13 Limpeza de versão no wrapper . . . . . . . . . . . . . . . . 52

3.1.14 TxnWrap : um algoritmo multiversão para manutenção de DW . . . 52

3.2 Algoritmo de propagação de rolagem . . . . . . . . . . . . . . 54

3.2 .1 Definições . . . . . . . . . . . . . . . . 55

3.2 .2 Propagação assíncrona . . . . . . . . . . . . . . . 56

3.2 .3 Rótulos de tempo . . . . . . . . . . . . . . . . . . . . 58

3.2.4 Propagação de Rolagem . . . . . . . . . . . . . . . . . . . . 59

3.3 Resumo dos Algoritmos . . . . . . . . . . . . . . . . . . . . 61 
4 Sugestão de um algoritmo assíncrono para atualizações de dados

4.1 Parâmetros que interferem nas atualizações . . . . . . . . . . . . . . 63

4.2 Proposição de um algoritmo assíncrono . . . . . . . . . . . . . . 64

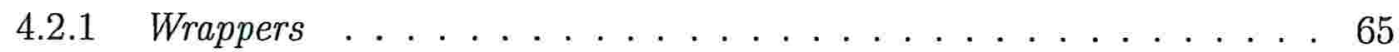

4.2 .2 Estrutura de-para do algoritmo de log de nível zero . . . . . . . . 66

4.2 .3 Módulo de Carga . . . . . . . . . . . . . . . . . . . . 68

4.2 .4 Data Warehouse . . . . . . . . . . . . . . . . . 69

4.2.5 Algoritmo de propagação para wrapper . . . . . . . . . . . 72

4.2.6 Algoritmo módulo de carga para data warehouse . . . . . . . . . . 73

5 Conclusão 74

5.1 Comparação entre algoritmos assíncronos . . . . . . . . . . . . . . 75

5.1 .1 Fontes de dados . . . . . . . . . . . . . . . . . . . . 75

5.1.2 Extração das atualizações de dados . . . . . . . . . . . . . . . 75

5.1.3 Atualização Incremental para warehouse . . . . . . . . . . . . . 75

5.1.4 Aplicação das atualizações incrementais para warehouse . . . . . . 76

5.1 .5 Visones ............................. 76

5.2 Dificuldades Encontradas . . . . . . . . . . . . . . . . . . 77

5.3 Trabalhos futuros . . . . . . . . . . . . . . . . . 77

\section{Lista de Figuras}

$1 \quad$ Arquitetura básica de data warehouse . . . . . . . . . . . . . . . . . . . 10

2 Visão Anômala de Warehouse com única fonte . . . . . . . . . . . . . . . 13

3 Visão Anômala de Warehouse com mútiplas fontes . . . . . . . . . . . . . . 14

4 Algoritmo ECA - $1^{\circ}$ exemplo . . . . . . . . . . . . . . 26

$5 \quad$ Algoritmo ECA - $2^{\circ}$ exemplo . . . . . . . . . . . . . . . 27

6 Algoritmo Strobe $-1^{0}$ Exemplo $\ldots \ldots \ldots 33$

7 Algoritmo Strobe $-2^{\circ}$ Exemplo . . . . . . . . . . . . 35

8 Algoritmo Sweep - Exemplo . . . . . . . . . . . . . . . . . . . . 44

9 Algoritmo Sweep - Exemplo - Continuação . . . . . . . . . . . . . . . . 44 
10 Modelo de Data Warehouse de nível zero . . . . . . . . . . . . . . . . . . 70

11 Arquitetura para atualizações de dados de data warehouse no modelo semântico de nível zero . . . . . . . . . . . . . . . . . . . . . 71

\section{Lista de Tabelas}

1 Tabela de comparação das complexidades dos algoritmos . . . . . . . . . 61

2 Formato geral de arquivo de $\log \ldots \ldots \ldots \ldots$

3 Exemplo de arquivo de log. . . . . . . . . . . . . 66

4 Forma geral da tabela de-para. . . . . . . . . . . . . . . . 66

5 Exemplo de relação de-para. . . . . . . . . . . . . . . . . . 67

$6 \quad$ Formato do log de saída. . . . . . . . . . . . . . . . . . 68 


\section{Agradecimentos}

Gostaria de agradecer a Deus por ter sido tão amigo e estar presente a todos os momentos da minha vida.

Ao meu orientador Professor João Eduardo por acreditar em meu trabalho e por todo o incentivo e confiança em mim depositados.

Gostaria de agradecer pela utilização do laboratório de banco de dados, que com seus recursos foi de fundamental importância para o desenvolvimento desta pesquisa.

Aos meus pais José e Jucyara que sempre me incentivaram, estando presente na minha vida para o que fosse necessário, e não me deixando nunca esquecer o quanto crescer é importante.

Ao meu Beto que durante esses anos esteve ao meu lado, em bons e maus momentos sempre me dando apoio e amor.

A minha irmã Gi com quem descobri um novo tipo de relação e uma nova-velha amiga que sempre me apoia.

A minha avó Zilah que sempre acha que as suas netas são as mais lindas e inteligentes do mundo.

Ao meu amigo Leandro, presente no meu dia-dia com seu ombro amigo e sempre pronto a dizer a verdade.

A Maria Cristina, minha amiga que sempre torceu pelo meu sucesso e nos deu um grande motivo de alegria nosso menino Mateus.

Aos meus amigos de mestrado no IME, Mateus, Alessandro, Aninha, Dani, Marcio, Said, Daniel, Francisco, Robson e tantos outros. Juntos superamos muitos obstáculos.

Aos meus amigos do laboratório Luciano, Marcio, Tadao, Isabel que nesta convivência diária, tornaram-se grandes amigos com que se pode contar e rir.

A Ariane por seu jeito, e por fazer parte do lado feminino neste laboratório tão masculino. Ao Seu Fabi e Dona Anízia que me ajudaram tanto quando cheguei em São Paulo e me tratam como se fosse membro da sua família.

A Fabiane que me acolheu na sua casa quando cheguei em São Paulo.

Ao pessoal administrativo do IME, secretárias de Pós e Graduação, biblioteca e xerox. 


\title{
Resumo
}

Os sistemas de data warehouse comerciais (SDWC) ${ }^{1}$ disponibilizam técnicas de armazenamento de dados para acesso eficiente e facilidades de consultas para o usuário final. As aplicações de SDWC possuem operações clássicas de sincronismo de dados, que não exigem uma atualização imediata dos dados replicados. Entretanto com a evolução da representação semântica dos dados em ambientes de banco de dados operacionais , as análises realizadas no SDWC requerem novas necessidades de sincronismo. Assim, existe um crescente interesse em SDWC que possam absorver rapidamente as atualizações do banco de dados operacional sem comprometer o processo de consulta aos dados armazenados no ambiente analítico. Com esses novos sistemas, o tempo de atualização dos dados entre o ambiente analítico e o ambiente operacional deve ser reduzido. Nossa pesquisa objetiva a caracterização dos limites dos algoritmos síncronos e assíncronos para atualização de dados em SDWC. Tal caracterização gerou subsídios para a criação de um processo simplificado de propagação das atualizações no SDWC.

\begin{abstract}
The Commercial Data Warehouse Systems (CDWS) avail storage techniques for efficient access and consultation facilities to end user. CDWS applications have got classic data synchronism operations that do not request an immediate replicated data update. Hence with the semantic representation evolution of data in the operational database environment, the accomplished analysis in CDWS request new synchronism necessities. As such, there is a growing interest in CDWS which can rapidly absorb the operational database updates without compromising the consultation process to data storage in an analytic environment. With theses new systems, data actualization time between the analytical environment and operational environment must be reduced. Our research aims at the characterization of the synchronous and asynchronous algorithm limits for data updating in a CDWS. Such characterization has generated subsidies for the making of simplified update propagation process in the CDWS.
\end{abstract}

\footnotetext{
${ }^{1}$ Termo em inglês amplamente utilizado em português como sinônimo de um ambiente computacional para armazenamento de um grande volume de dados históricos.
} 


\section{Introdução}

\subsection{Objetivo}

A dissertação de mestrado, objetiva numa primeira etapa, avaliar os algoritmos para consistência de atualizações de dados em Data Warehouse. Por meio da caracterização dos limites dos algoritmos de atualização síncronos e assíncronos existentes, pretende-se gerar subsídios para a construção de uma nova classe de algoritmos que tentem minimizar os problemas encontrados. Entre as aplicações de SDWC, muitas possuem operações de atualizações de dados nas quais o domínio da aplicação existente não exige uma atualização rigorosa dos dados usados nos SDWC. Porém, com a evolução da representação semântica ${ }^{2}$ dos dados em ambientes transacionais, as análises realizadas no data warehouse passaram a ter outras necessidades de atualização. Dentre alguns problemas que justificam essa nova necessidade, pode-se citar a globalização das companhias, que não permitem que o SDWC fique indisponível por uma grande janela de tempo. Por isso existe um crescente interesse em SDWC que possam absorver as atualizações do ambiente transacional $^{3}$ sem interromper o processo de consultas aos dados no ambiente analítico ${ }^{4}$. Nesse trabalho objetiva-se caracterizar os limites dos algoritmos existentes para atualização dos dados entre o ambiente analítico e o ambiente operacional e ainda apresentar uma sugestão de um algoritmo para a propagação de atualizações ocorridas no ambiente operacional para o analítico.

\subsection{Organização deste trabalho}

O primeiro capítulo aborda a caracterização do problema de atualizações de dados em data warehouse. Complementariamente descreve, de maneira resumida, o processo de carga convencional de data warehouse e quais os problemas decorrentes de se tornar este processo síncrono.

O segundo capítulo descreve algoritmos para atualizações síncronas de dados que tratam o problema de inconsistência dos dados.

O terceiro capítulo descreve algoritmos para atualizações assíncronas ou pseudoassíncronas de dados . Esse capítulo traz também um resumo das soluções assícronas e síncronas.

O quarto capítulo apresenta as contribuições do trabalho. Nele são apresentados parâmetros que interferem no processo de atualizações de dados e a proposta de uma alternativa para atua-

\footnotetext{
${ }^{2}$ Regras de associação entre os dados.

${ }^{3}$ Quando falamos em ambiente transacional estamos nos referindo ao banco de dados transacional juntamente com o sistema de informação que alimenta este banco de dados. Neste ambiente ocorrem as alterações, inserções e eliminaçōes de dados.

4 Ambiente analrtico refere-se so banco de dados analítico juntamente com o sistema de consultas existente sobre ele.
} 
lizações assíncronas de dados. O quinto capítulo traz a conclusão que é uma comparação entre o algoritmo assíncrono proposto com um importante algoritmo assíncrono apresentado no capítulo três.

\subsection{Introdução e caracterização do problema}

Um data warehouse é um repositório de informações integradas de fontes distribuídas, autônomas e normalmente heterogêneas para consultas e análises eficientes [ZGMW98]. Um data warehouse é um conjunto de bases de dados orientadas a conteúdo, integradas, variantes no tempo e não voláteis. O termo orientado a conteúdo indica que as informações no warehouse estão dispostas de acordo com a área de negócios ${ }^{5}$ da organização que o utiliza. O termo "integrado"refere-se ao fato que o warehouse integra dados derivados de vários sistemas funcionais diferentes da organização e provê uma única e consistente visão de toda a situação da organização. O termo "variante no tempo"significa que o warehouse é capaz de representar evolucão temporal dos dados, e as consultas podem ser baseadas em períodos de tempo. Os dados são "não-voláteis", considerando que eles sempre são incluídos no warehouse e raramente são eliminados do mesmo, mantendo todo o histórico da organização [MSRK98]. O conteúdo do data warehouse pode ser uma réplica, total ou parcial dos dados de uma ou mais fontes ${ }^{6}$ [SMKK99]. Desta maneira um data warehouse pode ser visto como um conjunto de visões materializadas das fontes de dados. A arquitetura de um SDWC é descrita pela figura 1.

Em cada fonte de dados um wrapper ${ }^{7}$ coleta os dados e os envia para o warehouse. Os wrappers são responsáveis por identificar as mudanças ocorridas nas fontes, transformá-las, filtrálas e enviá-las ao integrador. Se a fonte possui gatilhos relacionais (programas que são executados quando ocorre um evento), os wrappers podem simplesmente repassar os dados. No SDWC o integrador recebe os dados das fontes, executa as devidas conversões e traduções e adiciona informações extras como rótulos de tempo para análises históricas. O integrador combina os dados enviados pelas diferentes fontes, resolvendo os conflitos entre eles e mantendo-os na forma consistente. Finalmente os dados são enviados para o data warehouse. Como efeito, o data warehouse armazena uma visão materializada $(V M)$ das fontes [ZGMW98]. Nessa arquitetura considera-se que o data warehouse é constituído por visões materializadas das fontes de dados. É

\footnotetext{
${ }^{5}$ Setor do mercado onde a empresa atua.

${ }^{6}$ Fontes de dados são os sítios que contêm as informaçōes necessárias a serem analisadas em um data warehouse

${ }^{7}$ Pode-se traduzir wrapper como monitor. Porém, no texto será usado o termo em inglês por causa de sua ampla divulgação.
} 


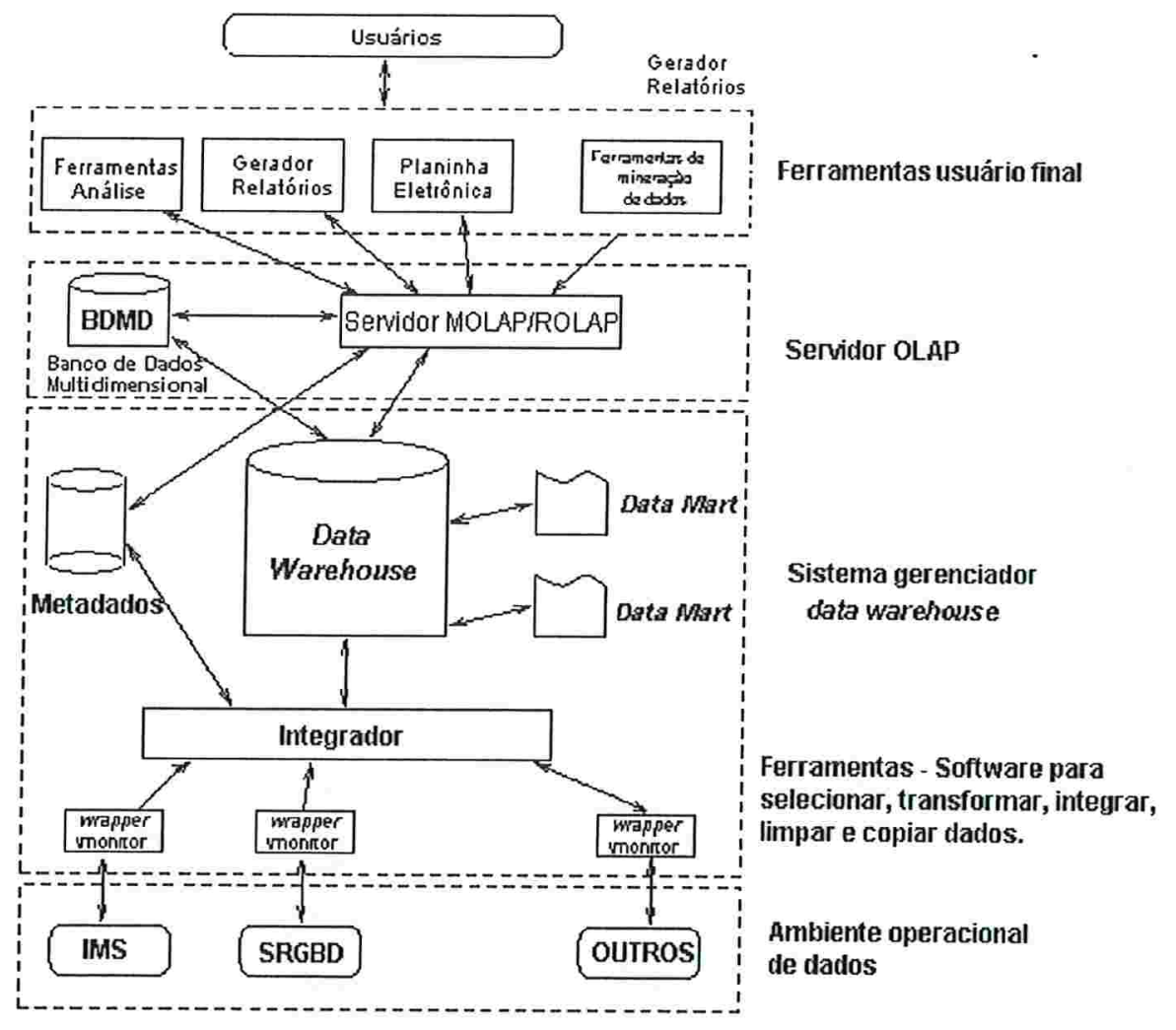

Figura 1: Arquitetura básica de data warehouse

sobre este aspecto de construção que o data warehouse será tratado durante o resto do trabalho. O metadado contém informações adicionais sobre criação, gerenciamento e uso do warehouse. Os dados do warehouse também podem ser acessados pelo servidor OLAP para dispor os dados como uma estrutura multidimensional para as utilização de aplicações de usuários finais ${ }^{8}$ tais como ferramentas de análise, gerador de relatórios, planilhas eletrônicas, ferramentas de mineração de dados. O servidor OLAP interpreta as consultas dos clientes e converte-as em consultas SQL que são necessárias para acessar os dados no data warehouse. Quando as consultas são respondidas, as ferramentes $O L A P$ passam visões multidimensionais dos dados para as aplicações dos usuários finais e essas ferramentas formatam os dados de acordo com as necessidades do usuário [SMKK99].

Após o processo inicial de carga do warehouse, ou seja, seu povoamento, mudanças ocorrerão

\footnotetext{
${ }^{8}$ As aplicaçōes de usuários finais são conhecidas como front-end.
} 
nas fontes e as visões materializadas do warehouse ficarão desatualizadas em relação às fontes de dados. Para manter, de forma eficiente, as visões materializadas do warehouse em relação às de dados nas fontes, as atualizações devem ser feitas de forma incremental [GMS].

A manutenção de visões materializadas difere da manutenção de visão tradicional, pois a definição da visão e as bases de dados estão desacopladas [ZGMHW95]. Usualmente as mudanças nas fontes de dados são propagadas periodicamente para as visões [QW97]. O processo de carga, segundo [AV98], é o fator de maior complexidade no warehouse. Na maioria dos sistemas de warehouse comerciais ${ }^{9}$ todas as alterações ocorridas nas fontes são acumuladas e periodicamente propagadas para o warehouse (por exemplo, diariamente). Essas alterações estão contidas em uma grande transação de atualização em lote (batch) chamada de transação de manutenção, que é tipicamente a única transação de atualização para as visões do warehouse [QW97]. Os warehouses comerciais se concentram em oferecer técnicas de armazenamento de dados para acesso eficiente e facilidades de consultas para o usuário final. Dessa maneira, devem executar as consultas e a transação de manutenção a fim de não gerar dados inconsistentes e uma não bloquear a outra. Para evitar esses problemas quando se executa a transação de manutenção, o warehouse fica indisponível para consultas (off-line) e as fontes ficam indisponíveis para atualizações de dados [ZGMW98]. Com a finalização do processo de carga (manutenção da visão), o warehouse conterá todas as atualizações geradas nas fontes de dados.

\subsubsection{Manutenção de visão síncrona de dados}

De forma diferente da solução apresentada acima, em que o SDWC fica indisponível para consulta, uma outra forma de manter as visões é a propagação imediata das transações após sua confirmação nas fontes de dados. Quando os dados no ambiente transacional sofrem alterações, o data warehouse precisa ser atualizado de acordo com tais mudanças. Conforme descrito anteriormente, o processo de atualizar a visão materializada em resposta às mudanças nas fontes de dados é chamado de manutenção de visão. A atualização de dados em ambientes distribuídos faz com que apareçam inconsistências entre os bancos analítico e transacional. Essa inconsistência é causada pelas formas de propagação das transações ocorridas nas fontes de dados [SMKK99].

Para não gerarem inconsistências, as formas de atualização de dados devem considerar os seguintes passos:

1. Propagação das mudanças das fontes de dados para o data warehouse para garantir que

\footnotetext{
${ }^{9}$ Chama-se de sistema de data warehouse comerciais os que estăo disponfveis e sendo usados no mercado.
} 
cada visão represente um estado consistente da base de dados.

2. Atualização das visões em resposta a essas mudanças ocorridas, usando o estado das fontes em que foi propagada a atualização.

3. Instalação das atualizações na visão no data warehouse na mesma ordem em que as mudanças ocorrem nas fontes.

As inconsistências irão aparecer no warehouse desde que as mudanças nas fontes sejam aleatórias e dinâmicas. Antes que o warehouse esteja pronto para computar a atualização da visão para mudanças já ocorridas, o estado das fontes pode ter mudado o que pode causar inconsistência nos dados.

A complexidade das atualizações on-line e o problema de inconsistência dos dados são ilustrados nos itens 1.3.2 e 1.3.3 descritos em [ZGMW98] e baseados no algoritmo de [BLT86]. Por simplificação assume-se que todas as fontes utilizam o modelo relacional e a visão materializada mantida no warehouse contém as chaves participantes de cada relação. Cada atualização é tratada como uma transação em cada uma das fontes de dados.

\subsubsection{Atualização de Warehouse com única fonte}

Sejam as relações na fonte

$$
\begin{array}{ccccccc} 
& \text { W } & \text { X } & & & \text { X } & \text { Y } \\
r_{1} & 1 & 2 & & r_{2} & &
\end{array}
$$

Seja a visão definida por $V=\pi_{W}\left(r_{1} \bowtie r_{2}\right)$. Inicialmente, temos a visão materializada $\mathrm{VM}=\emptyset$.

1. O warehouse recebe a atualização $\mathrm{U}_{1}=$ insert $\left(\mathrm{r}_{2}[2,3]\right)$

2. $\mathrm{O}$ warehouse envia a consulta $\mathrm{Q}_{1}=\mathrm{V}<U_{1}>=\pi_{w}\left(\mathrm{r}_{1} \bowtie[2,3]\right)$

3. O warehouse recebe $\mathrm{U}_{2}=$ insert $\left(\mathrm{r}_{1}[4,2]\right)$

4. O warehouse envia $\mathrm{Q}_{2}=\pi_{w}\left([4,2] \bowtie \mathrm{r}_{2}\right)$ para fonte. 
5. O warehouse recebe a resposta a consulta $Q_{1}$ que é $A_{1}=([1]$, [4]) que foi obtida sobre o estado corrente das relações

$\mathbf{r}_{1}=([1,2],[4,2])$ e $\mathbf{r}_{2}=([2,3])$. Então ele atualiza a visão fazendo $\mathrm{VM} \cup \mathrm{A}_{1}=([1],[4])$.

6. O warehouse recebe $A_{2}=[4]$ e atualiza a visão fazendo $\mathrm{VM} \cup \mathrm{A}_{2}=([1],[4],[4])$

O resultado da visão está incorreto.

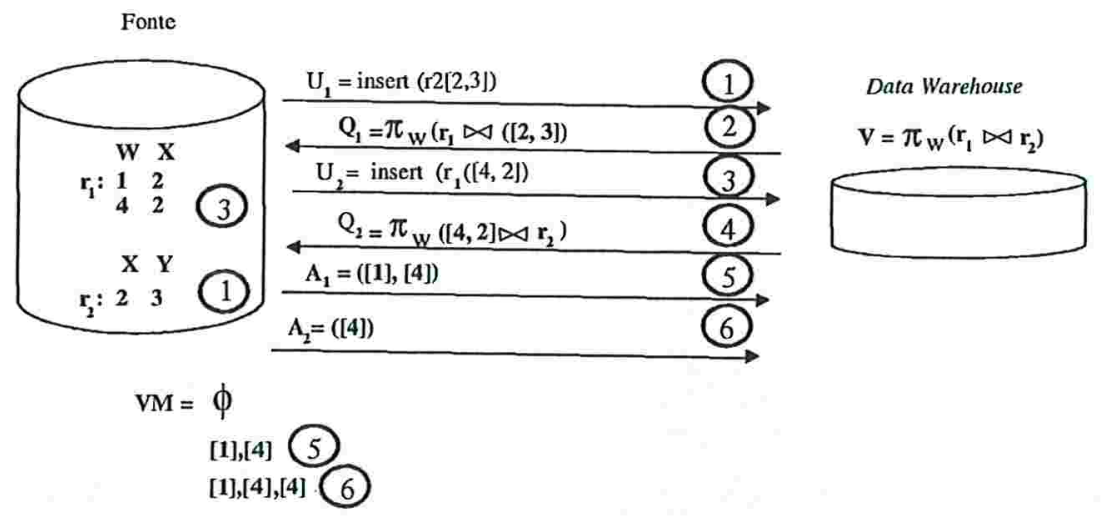

Figura 2: Visão Anômala de Warehouse com única fonte

\subsubsection{Atualização de warehouse com múltiplas fontes}

Sejam as relações nas fontes

$\begin{array}{rrrrrrrrrr} & & & \text { X } & & & \text { Y } & & & \text { Z } \\ & & \text { A } & \text { B } & & \text { B } & \text { C } & & \text { C } & \text { D } \\ & r_{1} & 1 & 2 & r_{2} & & & r_{3} & 3 & 4\end{array}$


Seja a visão da fonte definida por $V=\pi\left(r_{1} \bowtie r_{2} \bowtie r_{3}\right)$. Onde $r_{1}, r_{2}$ e $r_{3}$ são três relações residentes nas fontes $X, Y, Z$ Inicialmente a visão materializada $\mathrm{VM}=\emptyset$.

1. O warehouse recebe $\mathrm{U}_{1}=\operatorname{insert}\left(\mathrm{r}_{2}[2,3]\right)$

2. O warehouse gera consulta $\mathrm{Q}_{1}=\mathrm{V}<U_{1}>=\pi\left(\mathrm{r}_{1} \bowtie[2,3] \bowtie \mathrm{r}_{3}\right)$. Para executar $\mathrm{Q}_{1}$, o warehouse primeiro envia $Q_{1}^{1}=r_{1} \bowtie[2,3]$ para fonte $X$.

3. O warehouse recebe $A_{1}^{1}=[1,2,3]$ da fonte $\mathrm{X}$.

4. A consulta $Q_{1}^{2}=[1,2,3] \bowtie r_{3}$ é enviada para fonte $\mathrm{Z}$.

5. O warehouse recebe $\mathrm{U}_{2}=\operatorname{delete}\left(\mathrm{r}_{1}[1,2]\right)$ da fonte $\mathrm{X}$. Como a visão corrente é vazia, nenhuma ação é tomada para a remoção.

6. O warehouse recebe $A_{1}^{2}=[1,2,3,4]$ da fonte $\mathrm{Z}$.

7. Como não há consultas pendentes, então o warehouse atualiza VM aplicando $\mathrm{A}_{1}^{2} \mathrm{a}$ $\mathrm{VM}=[1,2,3,4]$. A visão final é incorreta.

\section{Fontes}

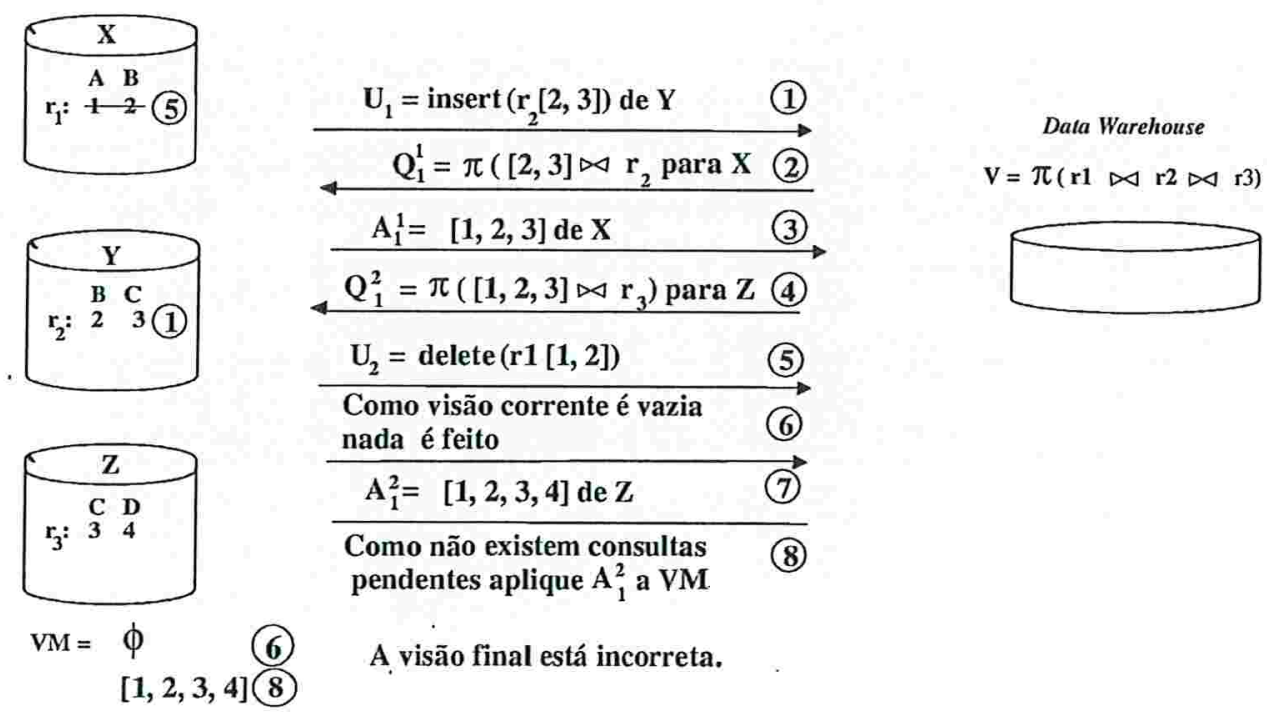

Figura 3: Visão Anômala de Warehouse com mútiplas fontes 


\subsubsection{Abordagens para se prevenir a inconsistência de atualizações de dados em data warehouse}

Para se prevenir a inconsistência de atualizações dos dados atualmente são usadas três abordagens diferentes:

A primeira abordagem consiste em fazer as atualizações baseadas em uma carga geral dos dados. Nesse tipo de atualização, o SDWC fica indisponível para uso. Nesta abordagem podemos incluir as seguintes técnicas:

- As cargas são realizadas de maneira convencional nos data warehouse comerciais, onde todo o SDWC fica parado durante o processo de carga. Existem intervalos fixos de tempo para essa atualização.

- Incorporação nas visões materializadas, de uma característica de automanutenção [GM95, GMS], ou seja, elas fazem sua própria manutenção sem que haja comunicação instantânea com as fontes de dados. Uma das técnicas para alcançar esse objetivo é fazer com que a manutenção da visão se torne local ao warehouse. Para isso, é necessário armazenar cópias de todas as relações no warehouse. Dessa maneira as atualizações poderiam ser feitas diretamente no warehouse. Essa técnica possui uma série de desvantagens: o espaço de armazenamento no warehouse para guardar todas as relações seria muito alto e poderiam aparecer inconsistências por causa da redundância dos dados. Além disso, dependendo do tipo de dados armazenados, como os dados de companhias, o warehouse teria que armazenar os dados de todas as companhias do mundo, pois se fossem copiadas apenas as companhias de interesse no momento, futuramente seria difícil responder uma consulta sobre uma nova companhia. O warehouse teria também que incorporar os dados de todas as fontes, e não somente os dados que lhe são interessantes.

Um exemplo desta abordagem seria a folha de pagamento de uma empresa. Como este evento acontece de forma periódica e bem definida, a atualização de acordo com a primeira abordagem é bastante adequada.

A segunda abordagem consiste em fazer as atualizações baseadas em atualizações síncronas e incrementais de dados. Nesse tipo de atualização, os sistemas ficam disponíveis para uso, porém é necessário tratar os problemas decorrentes de atualizações on-line, tais como inconsistência dos dados. Nesta abordagem podemos incluir as seguintes técnicas: 
- Cada atualização e todas as ações necessárias para a sua incorporação incremental no warehouse são feitas através de uma transação distribuída envolvendo o warehouse e todas as fontes de dados com quem se relaciona. Contudo transações distribuídas requerem um mecanismo de controle de concorrência global envolvendo todas as fontes, e tal mecanismo pode não ser plausível. Mesmo que este mecanismo exista, as fontes devem estar preparadas para tolerar os atrasos que aparecem em virtude do controle de concorrência global.

- Executar as atualizações de forma incremental síncrona, ou seja, no momento em que as atualizações ocorrem nas fontes elas são propagadas para o warehouse. Como mostrado anteriormente, essa abordagem pode gerar inconsistências nas atualizações dos dados. Cada atualização que ocorre no sistema transacional deve ser repassada para o data warehouse de forma que reflita os estados das fontes de dados e que não sejam afetadas por atualizações concorrentes [ZGMW98, ZGMHW95, AASY97, QW97, CCZR01].

Um exemplo desta abordagem seria um sistema formado por poucas relações onde a atualização de dados fosse crítica. Este processo pode se tornar crítico para um número maior de relações, devido a um grande número de atualizações interferentes.

A terceira abordagem consiste em fazer as atualizações baseadas em atualizações assíncronas e incrementais de dados. Neste tipo de atualização os sistemas ficam disponíveis e as atualizações são passadas de acordo com a necessidades do SDWC e, principalmente, evitam-se os problemas de inconsistência de dados. Nesta abordagem podemos incluir a seguinte técnica:

- A propagação das atualizações das fontes de dados para o warehouse divide-se em duas fases: a de propagação, em que os dados das fontes são tratados para poderem ser incorporados ao data warehouse e a de aplicação, na qual os dados são passados para o warehouse. Dessa maneira, o processo é feito assincronamente, sem a dependência entre as fontes e o data warehouse.

Um exemplo desta abordagem seria um sistema onde a atualização fosse crítica, porém não é viável um atualização síncrona. Desta maneira, assim que as condições do sistema permitissem os dados seriam atualizados. Um destes casos seria um sistema de compra e venda com avaliações diárias.

Neste trabalho foi adotada para a proposta de uma nova solução a abordagem assíncrona, pois através de suas características pode-se minimizar os problemas encontrados em atualizações de dados e contemplar o fato de não se poder aplicar soluções síncronas em todos os casos. 


\section{Algoritmos síncronos para atualizações de dados em data warehouse}

\subsection{Descrição geral dos algoritmos}

Neste capítulo serão apresentadas quatro famílias de algoritmos que visam manter a consistência de atualizações de dados no data warehouse de forma síncrona.

A família $E C A^{10}$ [ZGMHW95] foi projetada para ambiente centralizado. O algoritmo ECA e suas extensões executam cada atualização $U$ como uma transação. Todas as atualizações que ocorrerem até a incorporação de $U$ à visão serão tratadas como atualizações concorrentes. Dessa maneira, após a atualização $U$ ser executada para trazer os dados relevantes à visão e antes dela ser incorporada à visão do warehouse esta deve ser compensada para refletir os efeitos das atualizações concorrentes. Esta compensação é feita por meio de consultas às fontes de dados.

A família Strobe ${ }^{11}$ [ZGMW98] foi projetada para ambiente distribuído e evoluiu a partir da família $E C A$. A família Strobe trata cada atualização $U$ dependendo do ambiente transacional em que ele está inserida. Analogamente ao ECA o Strobe trata todas as atualizações que ocorrerem até a sua incorporação à visão como atualizações concorrentes. Dessa forma, antes que a atualização $U$ seja incorporada à visão do warehouse, ela deve ser compensada para refletir os efeitos das atualizações concorrentes. Um outro fator importante da família Strobe é que alguns de seus algoritmos necessitam que a visão do warehouse possua as chaves primárias das relações das fontes de dados que compõem a visão.

A família Sweep ${ }^{12}$ [AASY97] também foi projetada para ambiente distribuído. Baseia-se numa varredura em todas as fontes de dados. As fontes estão sempre numeradas, e quando se fala "a esquerda de uma fonte"trata-se das fontes de numeração inferior à fonte que gerou a atualização e, "a direita de uma fonte"refere-se às fontes de numeração superior. A varredura é feita nas fontes à direita da fonte que gerou a atualização e depois nas fontes à esquerda da fonte geradora da atualização. As atualizações que chegarem antes que uma atualização $U$ seja totalmente executada e incorporada na visão materializada, são colocadas em uma fila de espera e depois compensadas localmente de acordo com a fonte que enviou a resposta. É importante lembrar que, quando falamos em ambiente distribuído, para uma atualização ser executada e

\footnotetext{
${ }^{10}$ Sigla que, em português, significa algoritmos de compensaçāo Ansioso.

11 Sigla que, em português, significa algoritmos estroboscópicos.

12 Sigla que, em português, significa algoritmos de varredura.
} 
incorporada à visão, as fontes envolvidas na definição da visão devem ser consultadas e é nesse intervalo que aparecem as atualizações concorrentes.

A família Txn Wrap ${ }^{13}$ [JCR02] utiliza tabelas temporárias nos wrappers para manter as atualizações geradas pelas fontes para o data warehouse. Essas atualizações, ao serem armazenadas no wrapper, são rotuladas segundo a transação que as gerou. Isso garante que o algoritmo não precisará fazer compensação para transações interferentes. Cada atualização é feita por uma transação de alto nível que integra tanto a transação de atualização da fonte quanto sua correspondente transação de manutenção de data warehouse.

\subsubsection{Definições dos conceitos básicos comuns aos algoritmos}

Os conceitos básicos que serão aqui descritos podem ser comuns a todos os algoritmos, ou a pares deles. Quando se referirem a grupos de dois ou mais algoritmos os nomes dos mesmos serão ilustrados.

- As visões consideradas pelos algoritmos são formadas por um conjunto de Seleção-ProjeçãoJunção(SPJ) de forma geral $V=\left(\pi_{\text {atributosProjeção }}\left(\sigma_{\text {atributosSeleção }}\left(\mathrm{r}_{1} \bowtie \mathrm{r}_{2} \bowtie \ldots\right.\right.\right.$ $\left.\mathrm{r}_{n}\right)$ ). Na família Strobe as listas de projeções contêm os atributos-chave para cada uma das relações.

- As atualizações consideradas pelos algoritmos são de dois tipos: inserções e remoções. As alterações podem ser modeladas como remoções seguidas de inserções.

- Nas famílias ECA e Sweep é adotada uma técnica similar à descrita em [BLT86]. São utilizados sinais paras as tuplas onde: + denota uma atualização de inserção e - denota uma atualização de remoção. Os sinais das tuplas são propagados por meio de operações relacionais com as mesmas.

- Os algoritmos pressupõem que para fazer a manutenção de visão é utilizada a técnica de atualização imediata. Após a atualização ser confirmada na(s) fonte(s) de dados ela é repassada imediatamente para o data warehouse.

- Todas as atualizações executadas atomicamente na(s) fonte(s) de dados são enviadas como uma única unidade da(s) fonte(s) para o data warehouse.

\footnotetext{
${ }^{13} \mathrm{O}$ nome desse algoritmo faz referência à transação de atualização armazenada no wrapper.
} 
- Uma seqüência de operações que ocorre no mesmo sítio ${ }^{14}$ é considerada um evento. Existem dois tipos de eventos em cada fonte:

1. a fonte executa uma atualização e envia uma notificação para o warehouse.

2. a fonte de dados executa uma consulta usando suas relações e retorna a resposta para o warehouse.

Também há dois tipos de eventos no warehouse:

1. O warehouse recebe uma atualização e gera uma consulta para ser respondida pelas fontes.

2. O warehouse recebe a resposta de uma consulta e atualiza suas visões materializadas.

- A comunicação entre a(s) fonte(s) de dados e o data warehouse é uma Fila (FIFO). As atualizações são entregues na ordem em que são enviadas.

- As atualizações da(s) fonte(s) de dados são processadas pelos algoritmos na ordem de chegada no data warehouse.

- A(s) fonte(s) de dado(s), no caso dos algoritmos Strobe e Sweep são independentes umas das outras, ou seja, não existe comunicação entre elas e estas não são coordenadas.

- A complexidade para se desenvolver algoritmos de consistência de atualizações para warehouse está vinculada à heterogeneidade nas fontes de dados. Quanto maior a heterogeneidade gerada pelas fontes de dados, mais complexo o algoritmo se torna. As famílias Strobe e Sweep partem do pressuposto que existem três tipos de cenários transacionais:

1. Única atualização por transação: é o mais simples dos ambientes, no qual cada transação compreende uma única atualização e é notificada para o warehouse.

2. Transações locais na fonte: é uma seqüência de atualizações executadas na mesma fonte que, juntas, formam uma única transação. O objetivo é refletir todas essas ações atomicamente no warehouse. É assumido que cada fonte tem um escalonador serial local para todas as suas transações locais. Os lotes de atualizações que são passados juntos para o warehouse, são considerados nos ambientes de transações de fontes locais como uma transação única.

\footnotetext{
${ }^{14}$ Sítio é a traduçāo para a palavra site que se refere ao local onde as atualizações são executadas.
} 
3. Transações globais: neste cenário existem transações globais que contêm ações que são executadas em múltiplas fontes. É pressuposto que existe uma ordem de seriação global para as transações globais. O objetivo é refletir as transações globais atomicamente no warehouse. Dependendo da quantidade de dados que se tem sobre a transação, o objetivo pode ser alcançável.

- O estado de uma fonte após um evento $s e_{j}$ é $s s_{j}$, o estado do warehouse após o evento we é $w s_{i}$.

- No warehouse, o estado de uma visão materializada ( $V M)$ após um evento we $e_{i}$ é dado por $V\left[w s_{i}\right]$, em que $V$ é a definição de visão.

- São assumidos níveis de consistência para as visões materializadas do warehouse. Cada nível (1, 2, 3 e 4) descrito abaixo inclui o grau de consistência de seu anterior:

1. Convergência: para todas as finitas execuções $V\left[w s_{f}\right]=V\left[s s_{q}\right]$. Tem-se que $V\left[w s_{f}\right]$ é a visão do estado final do warehouse, ou seja após todas as atualizações cessarem. $V\left[s s_{q}\right]$ é a visão do estado final das fontes de dados. Então, após a última atualização e após todas as atividades terem cessado, a visão é consistente com a(s) fonte(s) de dados.

2. Consistência fraca: para todas as execuções e para todo $w s_{i}$ existe um vetor de estado de fonte $s s_{j}$ tal que $V\left[w s_{i}\right]=V\left[s s_{j}\right]$. Além disso, para cada fonte $x$ existe um escalonador serial de transações $T_{i}, R=T_{1}, \ldots . ., T_{k}$ tal que resultado $(R)[x]=$ $s s_{j}[x]$. Isso significa que cada estado do warehouse reflete um estado válido de fonte. Assim, existe um escalonamento seriável local em cada fonte que garante esse estado. Porém, cada fonte pode refletir um escalonamento seriável diferente e o warehouse pode refletir um conjunto diferente de transações confirmadas em cada fonte.

3. Consistência forte: existe um escalonador serial $R$ e um mapeamento $m$ dos estados do warehouse nos estados das fontes tal que: (a) $O$ escalonador serial $R$ é equivalente à execução atual das transações nas fontes. (b) Para todo $w s_{i}, m\left(w s_{i}\right)=s s_{j}$ para algum $j$ e $V\left[w s_{i}\right]=V\left[s s_{j}\right]$. (c) Se $w s_{i}<w s_{k}$, então $m\left(w s_{i}\right)<m\left(w s_{k}\right)$. Isso significa que cada estado do warehouse reflete um conjunto válido de estados de fonte, refletindo o mesmo escalonamento serial global, e a ordem dos estados do warehouse é a mesma das ações das fontes. 
4. Consistência completa: para todo $s s_{j}$ definido por $R$ existe um $w s_{i}$ tal que $m\left(w s_{i}\right)=$ $s s_{j}$, ou seja, existe uma completa preservação da ordem mapeada entre os estados da visão e os estados das fontes.

\subsection{Detalhes do algoritmo de compensação ansioso (Eager Compensation Algorithm)}

O algoritmo ECA [ZGMHW95] ${ }^{15}$ evita recomputar todas as visões materializadas e armazenar cópias das relações nas fontes de dados no warehouse. A idéia básica do algoritmo com seu pseudocódigo presente em 2.2.3 e ilustrado em 2.2.4, é adicionar às consultas enviadas para as fontes consultas de compensação para corrigir a atualizações concorrentes. Nesta solução assume-se que as mensagens são entregues em ordem, ou seja, quando uma atualização chega ao warehouse e são necessárias informações adicionais das fontes, como por exemplo se existirem junções na visão, o algoritmo contido no lado do warehouse gera uma consulta para as fontes que contêm as informações necessárias. Essas consultas têm precedência de criação e envio sobre novas atualizações que chegam ao warehouse. Dessa maneira, o algoritmo consegue detectar as anomalias que irão ocorrer caso outra atualização chegue antes da resposta à consulta. É também assumido que as fontes tratam pedidos feitos pelas consultas automaticamente.

\subsubsection{Definições dos conceitos básicos}

- O algoritmo explora o conceito de visões relacionais para garantir um certo tipo de consistência sem o uso dos bloqueios ${ }^{16}$ tradicionais. Em [BGMS92] encontram-se trabalhos relacionados ao assunto.

- A notação utilizada para os eventos de fonte e do warehouse são:

$S_{-} u p$ : a fonte executa uma atualização $U$ e envia notificação de atualização para o warehouse.

$S_{\_} q u$ : a fonte executa a consulta $Q$ usando o estado corrente das relações nas fontes base e envia a relação resposta $A$ para o warehouse.

W_up: o warehouse recebe uma atualização $U$, gera uma consulta $Q$ e a envia para a fonte onde será executada.

\footnotetext{
${ }^{15}$ Será usada a sigla em ingles em razão de seu conhecimento e de sua disseminaçāo.

16 Termo usado em controle de concorrência que significa que um recurso encontra-se reservado para uma determinada transação.
} 
$W_{\text {_ans: }}$ o warehouse recebe a relação resposta $A$ da consulta $Q$ e atualiza a visão baseada em $A$.

- Um evento arbitrário é denotado por e. Um evento de fonte é denotado por se. Um evento de warehouse é denotado por we. Tipos de evento são subscritos para indicar um evento específico, por exemplo: $S_{-} u p_{i}, W_{-} u p_{j}$. Para cada evento $e$, informações relevantes sobre o evento são denotadas por consulta(e), atualização(e) e resposta(e) que denotam, respectivamente, consulta, atualização e resposta associada a este evento. Se o evento $e$ é causado por outro evento, então gatilho(e) denota o evento que disparou $e$. O estado dos dados após um evento é denotado por estado(e).

- Existe um operador binário de evento "<"que significa precede a.

- Nas fontes, $Q\left[s s_{i}\right]$ é a resposta encontrada para uma consulta $Q$ nas relações bases existentes após o evento $s e_{i}$.

- O estado final no data warehouse é denotado por $w s_{q}$. O estado final das fontes é denotado por $s s_{p}$.

- Existem dois operadores binários "+" e "-" que operam sobre as relações com sinais nas tuplas. Os operadores são comutativos e associativos. O produto cartesiano $x$ é distributivo sobre "+" e"-".

- Para manter a visão sobre as relações, o algoritmo ECA gera consultas que contêm uma coleção de termos na seguinte forma:

$$
T=\pi_{p r o j}\left(\sigma_{\text {cond }}\left(\tilde{r}_{1} \bowtie \tilde{r}_{2} \bowtie \ldots \tilde{r}_{n}\right)\right)
$$

em que $\tilde{r}_{i}$ com $i=(1,2 \ldots n)$, é uma relação $r_{i}$ ou uma tupla de atualização $t_{i}$ de $r_{i}$.

A consulta é formada pelo somatório dos termos:

$$
Q=\sum_{i} t_{i}
$$

Nos algoritmos desta família as consultas sempre derivam de consultas que já estão sendo processadas e ainda não foram respondidas e/ou da definição da visão no data warehouse. Abaixo temos uma expressão de álgebra relacional que pode ser gerada em uma consulta.

$$
Q=\pi_{p r o j}\left(\sigma_{c o n d}\left(r_{1} \bowtie[2,3] \bowtie r_{3}\right)\right)+\pi_{p r o j}\left(\sigma_{c o n d}\left(-[1,2] \bowtie[2,3] \bowtie r_{3}\right)\right)
$$




\subsubsection{Descrição do Algoritmo ECA}

O algoritmo ECA com seu pseudocódigo presente em 2.2 .3 e ilustrado em 2.2.4, é um algoritmo de manutenção de visão incremental baseado no algoritmo de manutenção de visão centralizada de [BLT86]. O algoritmo ECA antecipa as anomalias que aparecem por causa do desacoplamento entre as atualizações das fontes de dados base e a modificação da visão, efetuando compensações para as anomalias a fim de garantir a correta manutenção da visão. Neste algoritmo, o warehouse possui um "conjunto de consultas pendentes"que é definido a seguir.

Quando um evento we é processado no warehouse, seja UQS(we) (unanswered query set) o conjunto de consultas não respondidas de $w e$, ou seja, o conjunto de todas as consultas que foram enviadas pelo warehouse antes que we ocorresse, mas cujas respostas não foram recebidas antes que we chegasse ao warehouse. Quando o warehouse receber uma atualização $U_{i}$ e o conjunto $U Q S$ não for vazio, esta atualização pode causar o resultado incorreto das consultas $Q_{j}$ que estão em UQS aguardando resposta. Essa incorreção aparece, pois as consultas $Q_{j}$ deveriam ter sido computadas antes de $U_{i}$, porém serão computadas depois de $U_{i}$. Dessa forma todas as consultas em $U Q S$ vão "enxergar"um estado de fonte que já reflete $U_{i}$. Para corrigir esse possível problema, o algoritmo ECA incorpora uma "consulta de compensação"para cada consulta contida em UQS. Essas consultas compensatórias corrigem os efeitos da atualização $U_{i}$ nas consultas existentes em UQS. A utilização de consultas compensatórias tem uma importante conseqüência: os resultados de uma consulta só podem ser aplicados à visão quando o resultado da mesma e de todas as consultas compensatórias tiverem sido recebidas. O ECA coleta as respostas intermediárias em uma relação temporária chamada COLLECT, e apenas atualiza a visão quando todas as respostas das consultas em $U Q S$ tiverem sido recebidas, ou seja, $U Q S=\emptyset$. Dessa maneira, ele previne estados inválidos de visões. 


\subsubsection{Algoritmo ECA}

\section{[ZGMHW95]}

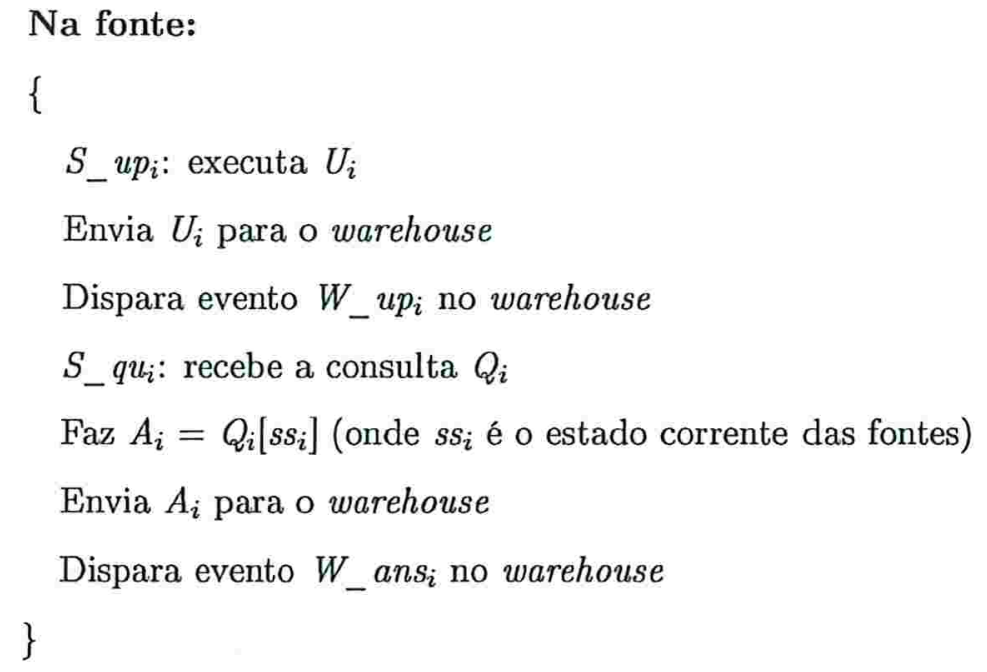

\section{No warehouse:}

\{

$W_{-} u p_{i}$ : recebe $U_{i}$

Faz $Q_{i}=V<U_{i}>-\sum Q_{j} \in U Q S Q_{j}<U_{i}>$

Envia $Q_{i}$ para a fonte

Dispara evento $S_{-} q u_{i}$ na fonte

$W_{-} a n s_{i}$ : recebe resposta da consulta $A_{i}$

$\mathrm{Faz}$ COLLECT $=$ COLLECT $+A_{i}$;

Se $U Q S=\emptyset$, então

\{

$V M=V M+C O L L E C T$

COLLECT «

\}

senão não faz nada

\} 


\subsubsection{Exemplos}

O algoritmo ECA garante a consistência forte, porém não é completo, pois a consistência completa descrita na seção 2.1.1 requer que todo estado de fonte seja refletido em algum estado da visão. Mas, no algoritmo, alguns estados das fontes podem ser perdidos enquanto o algoritmo recolhe as respostas das consultas.

1) Sejam as relações nas fontes:

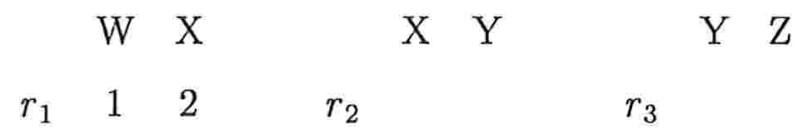

Seja a visão da fonte definida por $V=\pi_{w}\left(r_{1} \bowtie r_{2} \bowtie r_{3}\right)$.

Inicialmente a visão materializada $(V M)=\emptyset$ e $C O L L E C T=\emptyset$.

1. $\mathrm{O}$ warehouse recebe $\mathrm{U}_{1}=\operatorname{insert}\left(\mathrm{r}_{1},[4,2]\right)$

2. O warehouse envia $\mathrm{Q}_{1}=\mathrm{V}<U_{1}>=\pi_{w}\left(-[4,2] \bowtie \mathrm{r}_{2} \bowtie \mathrm{r}_{3}\right)$

3. O warehouse recebe $\mathrm{U}_{2}=\operatorname{insert}\left(\mathrm{r}_{3},[5,3]\right) \rightarrow \mathrm{UQS}=\mathrm{Q}_{1}$

4. O warehouse envia $\mathrm{Q}_{2}=\mathrm{V}<U_{2}>-Q_{1}<U_{3}>=\pi_{w}\left(r_{1} \bowtie \mathrm{r}_{2} \bowtie[5,3]\right)$

$-\pi_{w}\left([4,2] \bowtie \mathrm{r}_{2} \bowtie[5,3]\right)$

5. O warehouse recebe $\mathrm{U}_{3}=$ insert $\left(\mathrm{r}_{2},[2,5] \rightarrow \mathrm{UQS}=\mathrm{Q}_{1}, \mathrm{Q}_{2}\right.$

6. O warehouse envia $Q_{3}=\mathrm{V}<U_{3}>-Q_{1}<U_{3}>-Q_{2}<U_{3}>=\pi_{w}\left(\mathrm{r}_{1} \bowtie[2,5] \bowtie \mathrm{r}_{3}\right)-$ $\pi_{w}\left([4,2] \bowtie[2,5] \bowtie \mathrm{r}_{3}\right)-\pi_{w}\left(\mathrm{r}_{1}-[4,2] \bowtie[2,5] \bowtie[5,3]\right)$

7. O warehouse recebe $\mathrm{A}_{1}=[4]$. COLLECT $=\emptyset+([4])=([4]) \rightarrow \mathrm{UQS}=\mathrm{Q}_{2}, \mathrm{Q}_{3}$

8. O warehouse recebe $\mathrm{A}_{2}=[1]$. COLLECT $=[4]+[1]=([4],[1]) \rightarrow \mathrm{UQS}=\mathrm{Q}_{3}$

9. O warehouse recebe $A_{3}=\emptyset$. COLLECT $=([4],[1])+\emptyset=([4],[1]) \rightarrow$ UQS $=\emptyset$

10. O warehouse atualiza a visão: $\mathrm{VM}=\mathrm{COLLECT}+\emptyset=([1],[4])$ que está correto. 


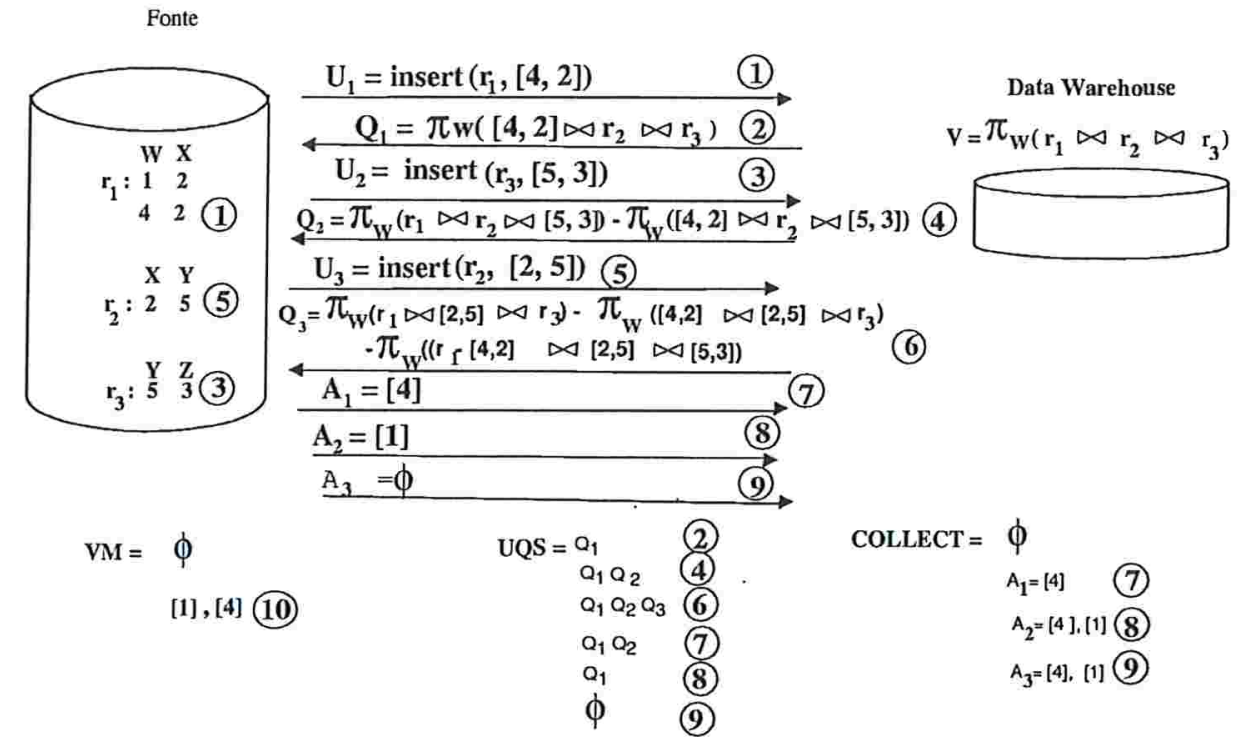

Figura 4: Algoritmo ECA - $1^{\circ}$ exemplo

\section{2) Sejam as relações nas fontes:}

$\begin{array}{ccccccc} & \text { W } & \text { X } & & \mathrm{X} & \mathrm{Y} \\ r_{1} & 1 & 2 & & r_{2} & 2 & 3 \\ & 4 & 2 & & & \end{array}$

Seja a visão da fonte definida por $V=\pi_{w}\left(r_{1} \bowtie r_{2}\right)$. Inicialmente, a visão materializada $(V M)=([4],[1])$ e COLLECT $=\emptyset$.

1. O warehouse recebe $\mathrm{U}_{1}=\operatorname{delete}\left(\mathrm{r}_{1},[4,2]\right)$

2. O warehouse envia $\mathrm{Q}_{1}=\mathrm{V}<U_{1}>=\pi_{w}\left(-[4,2] \bowtie \mathrm{r}_{2}\right) \rightarrow \mathrm{UQS}=\mathrm{Q}_{1}$

3. - $\mathrm{O}$ warehouse recebe $\mathrm{U}_{2}=\operatorname{delete}\left(\mathrm{r}_{2},[2,3]\right)$

4. $\mathrm{O}$ warehouse envia $\mathrm{Q}_{2}=\mathrm{V}<U_{2}>-\mathrm{Q}_{1}<U_{2}>=\pi_{w}\left(\mathrm{r}_{1} \bowtie-[2,3]\right)$ $-\pi_{w}(-[4,2] \bowtie-[2,3]) \rightarrow \mathrm{UQS}=\mathrm{Q}_{1}, \mathrm{Q}_{2}$

5. O warehouse recebe $A_{1}=\emptyset$. COLLECT $=\emptyset+A_{1}=\emptyset \rightarrow$ UQS $=Q_{2}$ 
6. O warehouse recebe $A_{2}=(-[4],-[1])$. COLLECT $=\emptyset+(-[4],-[1])=(-[4],-[1]) \rightarrow$ $\mathrm{UQS}=\emptyset$

7. $\mathrm{O}$ warehouse atualiza a visão: $\mathrm{VM}=\mathrm{VM}+\mathrm{COLLECT}=([1],[4])+(-[1],-[4])=\emptyset$ que está correto.

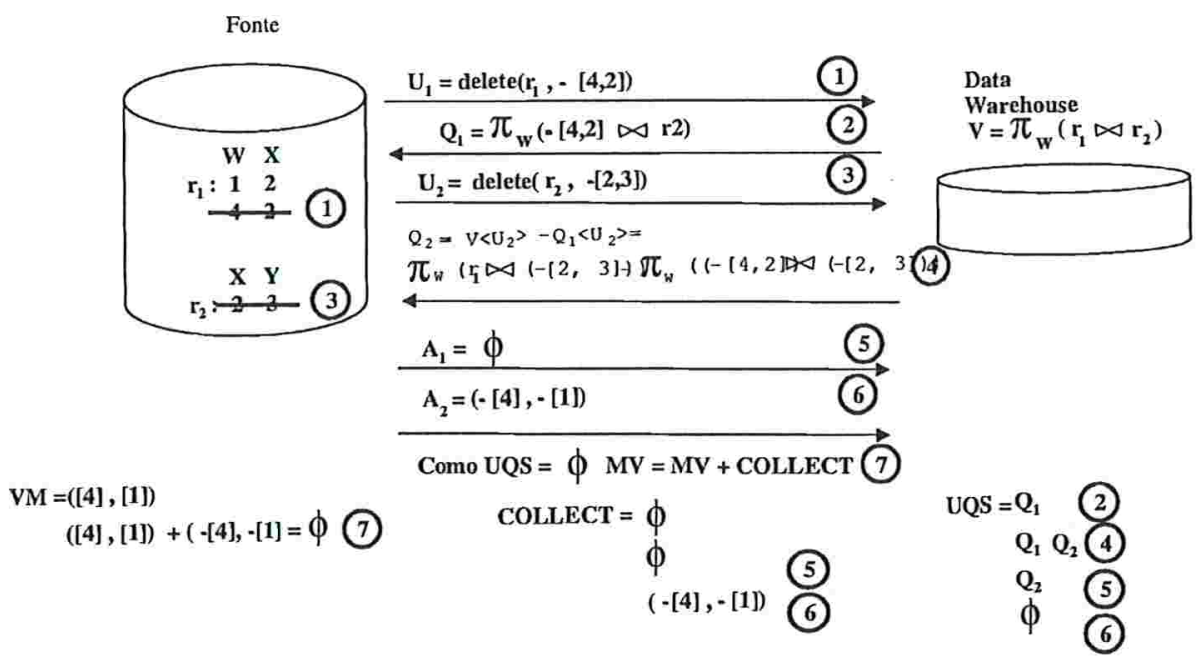

Figura 5: Algoritmo ECA - $2^{\circ}$ exemplo

O algoritmo ECA possui algumas variações que estão descritas em [ZGMHW95] e não serão abordadas no escopo deste trabalho.

\subsection{Propriedades da família ECA}

- São incrementais, ou seja, cada atualização no warehouse é baseada numa atualização da fonte em vez de recomputar toda a visão do warehouse.

- Eles não adicionam carga extra à fonte como bloqueios e rótulos de tempo.

- Quando a freqüência de atualização é baixa, o algoritmo ECA comporta-se da mesma forma que o algoritmo incremental de visão materializada de [BLT86] pois as consultas compensatórias são usadas apenas quando a resposta de uma consulta ainda não foi recebida antes que a próxima atualização ocorra nas fontes. 


\subsection{Família de Algoritmos Estroboscópicos (Strobe Algorithms Family)}

[ZGMW98]

\subsubsection{Definições dos conceitos básicos}

- Os algoritmos da família Strobe receberam este nome por causa das luzes estroboscópicas, pois eles periodicamente "congelam"as constantes mudanças das fontes em uma visão consistente no warehouse.

- A visão materializada $V M$ de uma visão $V$ é o estado corrente de $V$ no warehouse $V(w s)$. Quando uma visão é definida sobre múltiplas fontes, uma atualização em determinada fonte pode gerar uma consulta a múltiplas fontes. Como não se pode assumir que as fontes vão cooperar para responder a essa consulta, o warehouse deve decidir para onde enviar primeiro a consulta.

- Em transações globais, as atualizações podem ser entregues de diversas maneiras: o sítio que confirma a transação pode recolher todas as atualizações e enviá-las ou cada sítio pode enviar suas próprias atualizações uma vez que saibam que a transação global tenha sido confirmada.

- Pressupõe-se que duas mensagens enviadas por uma fonte são entregues na ordem em que foram enviadas. Porém, não há restrição para a ordem de entrega de mensagens de fontes diferentes, ou seja, as fontes não são coordenadas.

- Se duas mensagens são enviadas por rotas diferentes, o aspecto crucial não é que as mensagens cheguem em ordem, mas que elas sejam processadas em ordem. Para garantir esse aspecto, são adicionados números seqüenciais para todas as mensagens de cada uma das fontes. Dessa forma, o warehouse pode detectar a falta de uma mensagem e esperá-la antes de processar as outras mensagens que já chegaram ao warehouse.

- Cada estado do warehouse ws representa o conteúdo do warehouse em um dado momento. O estado do warehouse muda sempre que a visão é atualizada. Sejam $w s_{1} \ldots, w s_{f}$ estados do warehouse, pressupõe-se que existe um estado final do warehouse $w s_{f}$ quando todas as atividades cessam. 
- Seja $u$ o número de fontes identificadas unicamente por um identificador $x$ tal que $(1 \leq x \leq u)$. O estado das fontes $s s$ é um vetor que contém $u$ elementos e representa o estado de cada fonte em um dado momento.

- O estado de uma fonte $x$ é dado por $s s[x]$. Pressupõe-se que as atualizações da fonte são executadas de forma seriável por meio de todas as fontes, ou seja, existe um escalonador serial $S$ que representa a execução das atualizações.

- O estado final das fontes depois que $S$ termina é denotado por $s s_{q} . V(s s)$ é o resultado de computar sobre a visão $V$ o estado de fonte $s s$.

- Cada transação confirmada em uma fonte a leva de um estado consistente para outro. Para algum escalonador serial $R$, usa-se resultado $(R)$ para referir-se ao vetor de estado das fontes que resulta da sua execução.

Pressupõe-se que a visão do warehouse é inicialmente sincronizada com o estado da fonte, $V\left(s s_{0}\right)=V\left(w s_{0}\right)$. Os níveis de consistência descritos na seção 2.1.1 definem o que significa o algoritmo ser consistente em um ambiente no qual as atividades das fontes são desacopladas das visões do warehouse.

- Dada uma consulta $Q$ que necessita de resposta, a função proxima-fonte(Q) retorna o par $\left(x, Q^{i}\right)$ no qual $x$ é a próxima fonte a ser contatada e $Q^{i}$ é a porção da consulta $Q$ que será executada em $x$. Quando $Q$ estiver completa, o valor de $x$ é nil. $A^{i}$ será a resposta recebida no warehouse em resposta à subconsulta Q. Para consultas do tipo ProjeçãoSeleção-Junção, o procedimento proxima-fonte sempre irá escolher a relação com a qual pode ser efetuada a junção com a parte conhecida da consulta.

- Dada uma consulta $Q$, o procedimento avalia-fonte será o procedimento responsável por computar toda a consulta, ou seja, ele determina a próxima porção da consulta (subconsulta) e a computa até que a resposta final da consulta seja calculada. O procedimento avalia-fonte pode retornar uma resposta incorreta quando existem transações concorrentes nas fontes que interferem na evolução da consulta. A idéia chave do algoritmo Strobe é armazenar as atualizações que ocorrem durante a evolução da consulta e mais tarde compensá-las. 
Avalia-Fonte(Q): retorna resposta a uma consulta $Q$

inicio

$\mathrm{i}=0 ; W Q=Q ; A^{0}=Q$ "WQ é a consulta corrente (a subconsulta)"

$\left(x, Q^{1}\right) \longleftarrow$ proxima-fonte $(W Q)$;

Enquanto $x$ é diferente de nil

Faça $\mathrm{i}=\mathrm{i}+1$;

Envie $Q^{i}$ para a fonte $x$;

Quando $x$ retornar $A^{i}$, faça $W Q=W Q<A^{i}>$

Faça $\left(x, Q^{i+1}\right) \longleftarrow$ proxima-fonte $(W Q)$;

Retorne $\left(A^{i}\right)$;

fim.

- O conjunto de consultas não-respondidas $(U Q S)$ é o conjunto de todas as consultas que o warehouse enviou para alguma fonte, mas que ainda não recebeu resposta.

- A operação remove-chave $\left(R, U_{i}\right)$ remove da relação $R$ todas as tuplas cujos atributos-chave tenham os mesmos valores que $U_{i}$.

- $\quad V<U>$ denota a expressão da visão $V$ com a tupla $U$ substituída pelas relações de $U$.

\subsubsection{Descrição do algoritmo Strobe}

O algoritmo Strobe descrito em 2.4.3 e ilustrado em 2.4.4 processa atualizações na ordem em que elas chegam, enviando consultas para as fontes quando for necessário. Essas atualizações não são executadas imediatamente na visão materializada $(V M)$. Em vez disso, é gerada uma lista de ações $(A L)$ para ser executada na visão. A $V M$ só é atualizada quando se tem certeza que se pode aplicar todas as ações de $(A L)$, como uma única transação no warehouse. Isso levará o warehouse para um estado consistente. Este processo ocorre quando não existem consultas pendentes de respostas, e todas as atualizações recebidas foram processadas.

Quando o warehouse recebe uma remoção, a parte do algoritmo Strobe localizada no data warehouse gera uma ação de remoção para as tuplas correspondentes, que tem o mesmo valor de chave, na $V M$. Quando uma inserção chega, o warehouse precisa gerar e processar uma consulta, usando o procedimento avalia-fonte $(Q)$. Enquanto a consulta $Q$ está sendo respondida pelas 
fontes, outras atualizações podem chegar ao warehouse. Dessa maneira, a resposta da consulta obtida pode estar incorreta.

Para fazer uma compensação, existe um conjunto de pendências pending(Q) que contém as atualizações que ocorrem enquanto a consulta $Q$ é processada. Quando a resposta de $Q$ chega ao warehouse, ela é totalmente compensada. Feito esse processo, uma ação de inserção é gerada para $V M$ e é colocada na lista de ações $(A L)$.

O algoritmo Strobe garante consistência forte para ambiente no qual cada atualização é uma transação.

\subsubsection{Algoritmo Strobe}

\section{Em cada fonte:}

\{

Após executar a atualização $U_{i}$ envie $U_{i}$ para o warehouse

Se receber a consulta $Q_{i}$, compute a resposta $A^{i}$ sobre $s s[x]$

(estado corrente de $x$ )

Envie $A^{i}$ para o warehouse.

\}

\section{No warehouse:}

\{

Inicializa $A L$ como conjunto vazio $<>$

Quando receber uma atualização $U_{i}$

Se $U_{i}$ for uma remoção

$\forall Q_{j} \in U Q S$ adicione $U_{i}$ para pending $\left(Q_{j}\right)$;

Insira remove-chave $\left(V M, U_{i}\right)$ em $A L$;

Se $U_{i}$ for uma inserção

Faça $Q_{i}=V<U_{i}>$ e faça pending $\left(Q_{i}\right)=\emptyset ;$

Faça $A^{i}=$ avalia-fonte $\left(Q_{i}\right)$;

$\forall U_{j} \in \operatorname{pending}\left(Q_{i}\right)$, aplique remove-chave $\left(\mathrm{A}_{i}, \mathrm{U}_{j}\right)$;

Adicione $\operatorname{insert}\left(V M, \mathrm{~A}_{i}\right)$ a $A L$;

Quando $U Q S=\emptyset$, aplique $A L$ a $V M$ como uma única transação sem tuplas repetidas Zerar $A L=\emptyset$;

\} 


\subsubsection{Exemplos}

1) Sejam as relações nas fontes

$\begin{array}{rrrrrrrrr} & \text { A } & \text { B } & & \text { B } & \text { C } & & \text { C } & \text { D } \\ r_{1} & 1 & 2 & r_{2} & & & & 3 & 4\end{array}$

Seja a visão da fonte definida por $V=\pi\left(r_{1} \bowtie r_{2} \bowtie r_{3}\right)$ em que $\mathrm{r}_{1}, \mathrm{r}_{2}$ e $\mathrm{r}_{3}$ são três relações residentes nas fontes $X, Y, Z$. Inicialmente a visão materializada $(V M)=\emptyset$ e $A L=\emptyset$.

1. O warehouse recebe $\mathrm{U}_{1}=\operatorname{insert}\left(\mathrm{r}_{2},[2,3]\right)$

2. O warehouse gera consulta $\mathrm{Q}_{1}=\mathrm{V}<U_{1}>=\pi\left(\mathrm{r}_{1} \bowtie[2,3] \bowtie \mathrm{r}_{3}\right)$. Para executar $\mathrm{Q}_{1}$, o warehouse primeiro envia $Q_{1}^{1}=\mathrm{r}_{1} \bowtie[2,3]$ para a fonte X.

3. $\mathrm{O}$ warehouse recebe $\mathrm{A}_{1}^{1}=[1,2,3]$ da fonte $\mathrm{X}$.

4. A consulta $Q_{1}^{2}=[1,2,3] \bowtie \mathrm{r}_{3}$ é enviada para a fonte $\mathrm{Z}$.

5. $\mathrm{O}$ warehouse recebe $\mathrm{U}_{2}=\operatorname{delete}\left(\mathrm{r}_{1},[1,2]\right)$ da fonte $\mathrm{X}$. Ele primeiro adiciona $\mathrm{U}_{2}$ a pending $\left(Q_{1}\right)$ e então adiciona remove-chave $\left(\mathrm{VM}, \mathrm{U}_{2}\right)$ para $\mathrm{AL}$. A lista de ações resultante é igual a $<$ remove-chave $\left(\mathrm{VM}, \mathrm{U}_{2}\right)>$.

6. - O warehouse recebe $\mathrm{A}_{1}^{2}=[1,2,3,4]$ da fonte $\mathrm{Z}$.

7. Como pending $\left(Q_{1}\right)$ não é vazio, o warehouse aplica remove-chave $\left(\mathrm{A}_{1}^{2}, \mathrm{U}_{2}\right)$ e a resposta é $\mathrm{A}_{1}^{2}=\emptyset$. Nada é adicionado à $\mathrm{AL}$.

8. Como não há consultas pendentes, então o warehouse atualiza VM aplicando $\mathrm{AL}=\left\langle\right.$ remove-chave $\left(\mathrm{VM}, \mathrm{U}_{2}\right)>$ na visão materizaliada, resultando em $\mathrm{VM}=\emptyset$. A visão final é correta e possui consistência forte com as fontes de dados. 


\section{Fontes}

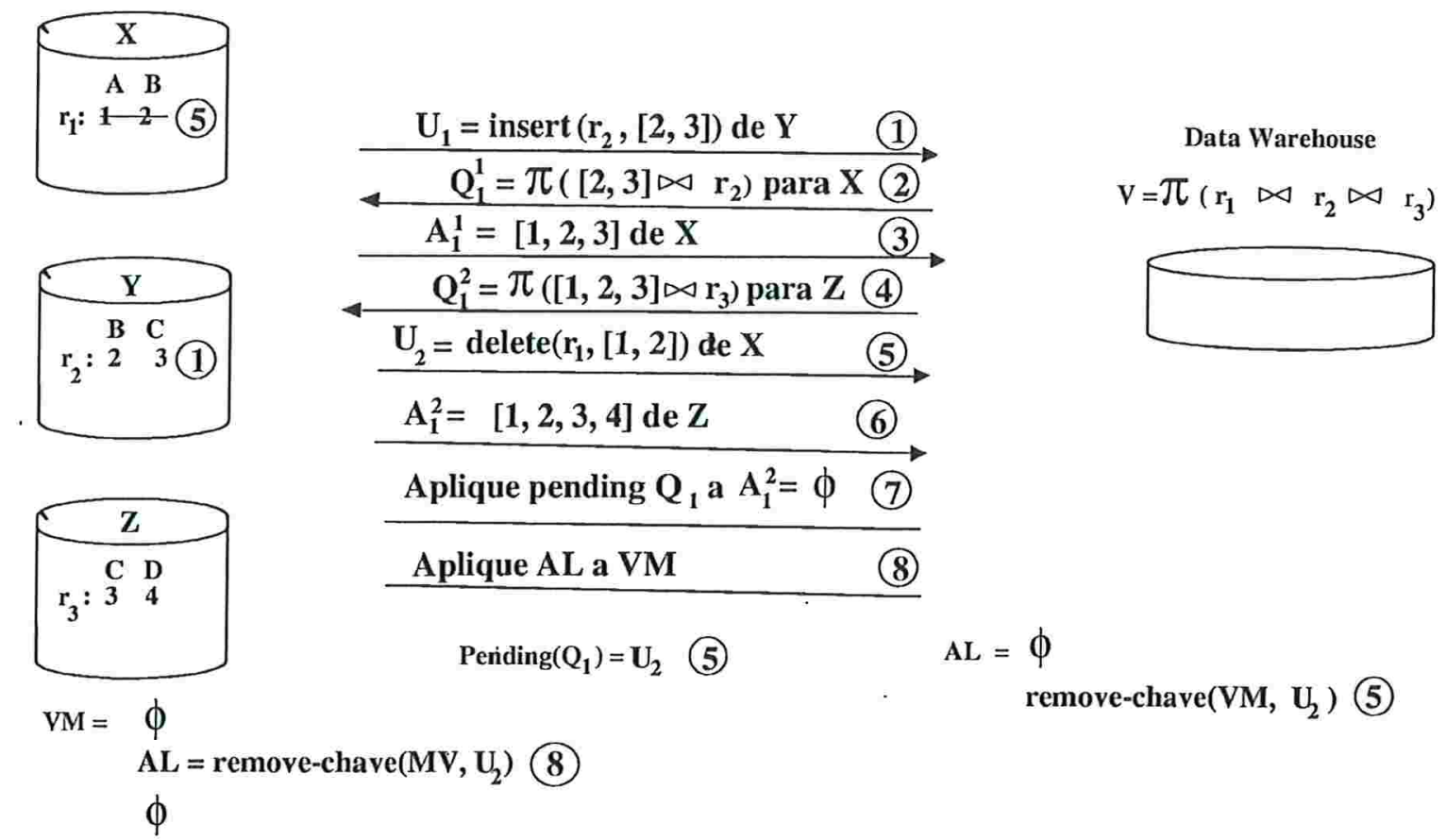

Figura 6: Algoritmo Strobe $-1^{\circ}$ Exemplo

2) Sejam as relações nas fontes

$\begin{array}{lllllllll} & \text { A } & \text { B } & & \text { B } & \text { C } & & \text { C } & \text { D } \\ r_{1} & 1 & 2 & r_{2} & & & & 3 & 4\end{array}$

Seja a visão da fonte definida por $V=\pi\left(r_{1} \bowtie r_{2} \bowtie r_{3}\right)$ em que $\mathrm{r}_{1}, \mathrm{r}_{2}$ e $\mathrm{r}_{3}$ são três relações residentes nas fontes $X, Y, Z$. Inicialmente, a visão materializada $(V M)=\emptyset \mathrm{e} A L=\emptyset$.

1. $O$ warehouse recebe $U_{1}=\operatorname{insert}\left(\mathrm{r}_{2},[2,3]\right)$ da fonte $Y$

2. O warehouse gera consulta $\mathrm{Q}_{1}=\mathrm{V}<U_{1}>=\pi\left(\mathrm{r}_{1} \bowtie[2,3] \bowtie \mathrm{r}_{3}\right)$. Para executar $\mathrm{Q}_{1}$, o warehouse primeiro envia $Q_{1}^{1}=\mathrm{r}_{1} \bowtie[2,3]$ para a fonte $\mathrm{X}$.

3. O warehouse recebe $A_{1}^{1}=[1,2,3]$ da fonte $\mathrm{X}$.

4. A consulta $Q_{1}^{2}=[1,2,3] \bowtie r_{3}$ é enviada para a fonte $\mathrm{Z}$. 
5. O warehouse recebe $\mathrm{U}_{2}=\operatorname{insert}\left(\mathrm{r}_{1}[5,2]\right)$ da fonte $\mathrm{X}$.

6. O warehouse gera consulta $\mathrm{Q}_{2}=\mathrm{V}<U_{2}>=\pi\left([5,2] \bowtie \mathrm{r}_{2} \bowtie \mathrm{r}_{3}\right)$. Para executar $\mathrm{Q}_{2}$, o warehouse primeiro envia $Q_{2}^{1}=[5,2] \bowtie \mathrm{r}_{2}$ para fonte a $\mathrm{Y}$.

7. $\mathrm{O}$ warehouse recebe $\mathrm{U}_{3}=\operatorname{delete}\left(\mathrm{r}_{1},[1,2]\right)$ da fonte $\mathrm{X}$. Primeiro adiciona $\mathrm{U}_{3}$ a pending $\left(Q_{1}\right)$ e pending $\left(Q_{2}\right)$ então, adiciona remove-chave $\left(\mathrm{VM}, \mathrm{U}_{3}\right)$ à $\mathrm{AL}$.

8. $\mathrm{O}$ warehouse recebe $\mathrm{A}_{2}^{1}=[5,2,3]$ da fonte $\mathrm{Z}$. O warehouse primeiro envia $\mathrm{Q}_{2}^{2}=[5,2,3] \bowtie \mathrm{r}_{3}$ para fonte $\mathrm{Y}$.

9. $\mathrm{O}$ warehouse recebe $\mathrm{A}_{1}^{2}=[5,2,3]$ da fonte $\mathrm{Z}$. Como pending $\left(Q_{1}\right)$ não está vazio, aplique remove-chave $\left(A_{1}^{2}, U_{3}\right)=\emptyset$. Nada é adicionado a $A L$.

10. O warehouse recebe $\mathrm{A}_{2}^{2}=[5,2,3,4]$ da fonte $\mathrm{Z}$. Como pending $\left(Q_{2}\right)$ não está vazio, aplique remove-chave $\left(A_{2}^{2}, U_{3}\right)=[5,2,3,4]$. Então insira insert(MV, $\left.A_{2}^{2}\right)$ em $A L$.

11. Como não há consultas pendentes, então o warehouse atualiza $\mathrm{VM}$ aplicando $\mathrm{AL}=$ $<$ remove-chave $\left(\mathrm{VM}, \mathrm{U}_{3}\right)$, insert $\left(\mathrm{MV}, \mathrm{A}_{2}^{2}\right)>$.

A VM $=[5,2,3,4]$ final é correta e com consistência forte com as fontes de dados.

\subsection{Algoritmo Estroboscópico Completo (Complete Strobe Algorithm)}

Um problema com os algoritmos da família Strobe é que, se existem atualizações constantes, os algoritmos podem não encontrar um estado onde UQS (conjunto consultas pendentes) é vazio para que a visão materializada possa ser atualizada. Para resolver esta questão, existe um quarto algoritmo da família Strobe chamado $C$-Strobe ${ }^{17}$, que pode atualizar o warehouse após alguma atualização da fonte ou um lote de atualizações.

Para forçar uma atualização da $V M$ após uma atualização $U_{i}$ chegar ao warehouse, é necessário computar a visão resultante, porém outras atualizações concorrentes nas fontes podem complicar o problema. Por exemplo: se a atualização $U_{i}$ for uma inserção para computar a próxima $V M$, o warehouse tem que enviar uma consulta $Q_{i}$ para as fontes.

Enquanto a resposta $A_{i}$ da consulta não é calculada, outras atualizações podem chegar ao warehouse e deverão ser compensadas para manter a resposta $A_{i}$ correta. Se essas atualizações

\footnotetext{
${ }^{17}$ Será usada a sigla em inglês em razão de seu conhecimento e sua disseminação.
} 

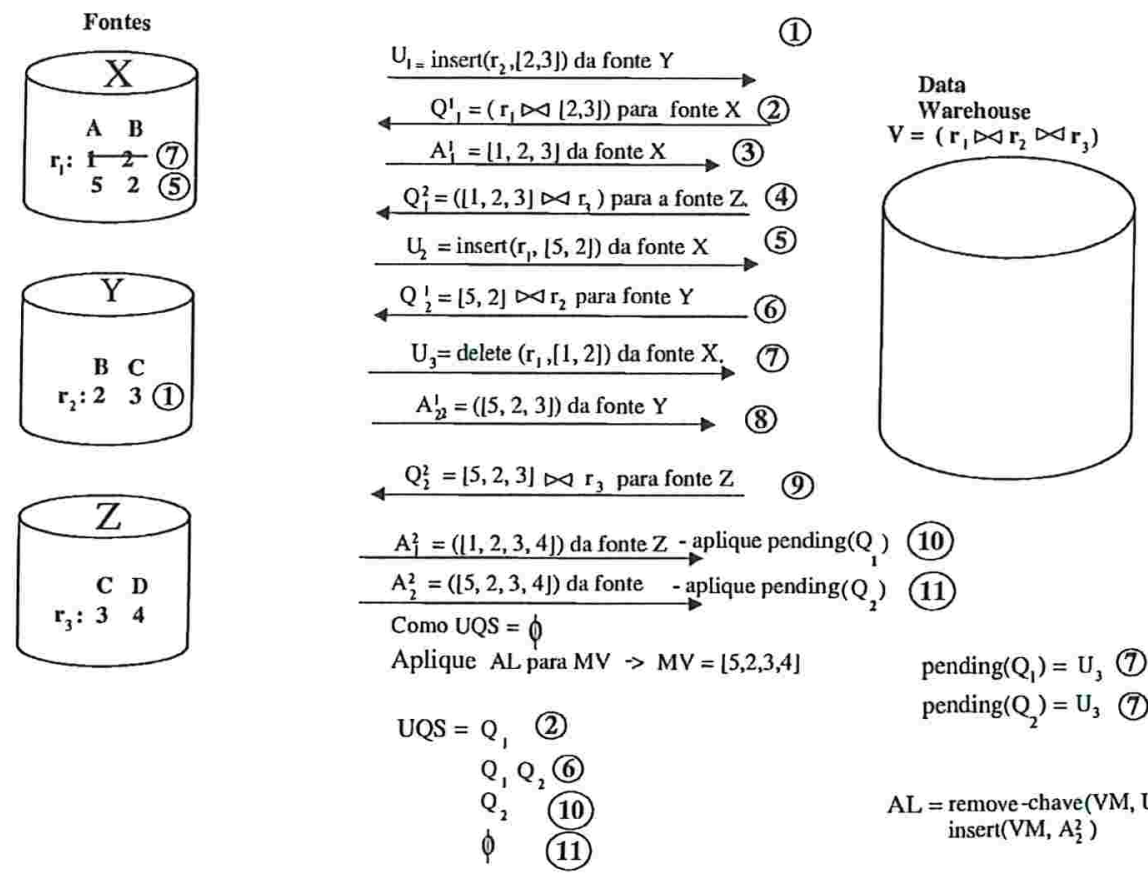

Figura 7: Algoritmo Strobe $-2^{\circ}$ Exemplo

forem inserções, deve-se apenas remover as tuplas correspondentes de $A_{i}$. Se a atualização for uma remoção, o warehouse pode necessitar adicionar tuplas à resposta $A_{i}$. Mas, para computar essas tuplas, uma nova consulta será gerada para as fontes.

Quando a resposta para as consultas intermediárias chegarem ao warehouse a visão pode ser materializada. A descrição completa desse algoritmo e de outras variações do algoritmo Strobe estão descritas em [ZGMW98].

\subsection{Família de algoritmos de varredura (Sweep Algorithm Family)}

\subsubsection{Definição dos conceitos básicos}

[AASY97]

No algoritmo Sweep ${ }^{18}$ é adotado o modelo de data warehouse apresentado em [ZGMW96, HZ96a, HZ96b]. Nesse modelo, as atualizações ocorrem nas fontes de dados e são classificadas como mostrado na seção 2.1.1. Nos algoritmos descritos, pressupor-se-á que as atualizações tratadas pelo data warehouse compreenderão os ambientes de Única atualização por transação e

\footnotetext{
${ }^{18}$ Será usada a sigla em inglês, por ser mais conhecida e disseminada.
} 
Transaçôes locais na fonte podendo ser estendidos para o ambiente de Transações Globais.

- A arquitetura do warehouse consiste de $n$ sítios para fontes de dados e um sítio para armazenar e manter a visão materializada do data warehouse.

- A comunicação entre cada fonte de dados e o warehouse é pressuposta como sendo uma FIFO ${ }^{19}$ confiável, ou seja, mensagens não são perdidas e são entregues na ordem em que são enviadas. Nenhuma suposição é feita sobre a comunicação entre fontes.

- O modelo de dados pressuposto para cada fonte é o modelo relacional, e cada uma pode armazenar qualquer número de relações, mas conceitualmente pressupõe-se uma relação única $R_{i}$ para cada fonte $i$.

- Cada fonte executa suas atualizações de maneira independente, ou seja, não são sincronizadas, sendo que cada uma dessas atualizações é executada atomicamente e monitorada.

- Todas as atualizações executadas atomicamente nas fontes de dados são enviadas como uma unidade atômica da fonte para o data warehouse.

- Nenhuma hipótese é pressuposta sobre as relações-base conterem os atributos-chave.

- Cada tupla na visão materializada possui um contador que indica de quantas maneiras diferentes a mesma tupla pode ser derivada da definição da visão dada e das relações fonte.

\subsubsection{Descrição do Algoritmo Sweep}

O algoritmo Sweep descrito em 2.6 .3 e 2.6 .4 e ilustrado em 2.6.5 é baseado em correção de erros síncronos, isto é, ele elimina os efeitos das atualizações concorrentes logo que elas são detectadas pelo data warehouse. Esta técnica é utilizada para atualizar a visão materializada do data warehouse incrementalmente para cada atualização das fontes de dados.

A visão materializada é atualizada na ordem das atualizações que são confirmadas nas fontes de dados e que chegam ao data warehouse. Dessa forma, para uma atualização $u$, o algoritmo garante que o efeito de todas as atualizações que chegarem ao data warehouse antes de $u$ serão

\footnotetext{
${ }^{19}$ Fila - Estrutura de dados onde a ordem de retirada dos elementos é a igual o ordem de inserção dos mesmos.
} 
refletidas na visão materializada, mas nenhuma das atualizações que chegarem depois de $u$ serão refletidas nessa visão. Dessa maneira o algoritmo garante consistência completa.

Cada fonte de dados possui um componente servidor de consulta para facilitar a manutenção de visão incremental no data warehouse. O servidor essencialmente provê serviços para tratar as atualizações ocorrendo nas fontes de dados e para responder consultas incrementais iniciadas no data warehouse. O módulo servidor é composto basicamente de dois processos (threads) correspondendo aos dois tipos de eventos de entrada que podem ocorrer nas fontes:

1. Uma atualização $\Delta R$ que pode ocorrer na relação $R$.

2. Uma requisição para computar uma nova visão incremental $\Delta V$.

Pressupõe-se que as requisições ao servidor são processadas seqüencialmente, isto é uma requisição é completamente executada antes de se executar a próxima. O servidor processa o evento interno $\Delta R$ enviando a atualização para o warehouse. Uma solicitação de consulta do data warehouse é computada fazendo a junção da relação nas fontes de dados $R$ com a resposta parcialmente computada $\Delta V$ incluída na consulta. O resultado da junção é enviado de volta para o data warehouse.

Deve-se observar que a junção na fonte de dados deve ser sincronizada com as atualizações locais que estão ocorrendo nas fontes. Para fazer a manutenção da visão, o data warehouse usa um módulo de software MudançaVisão. A função principal desse módulo, que é chamado por cada atualização $(\Delta R, i)$ recebida no data warehouse, é garantir que a mudança da visão irá refletir todas as atualizações nas fontes de dados até $(\Delta R, i)$, mas não refletirá nenhuma das atualizações que chegarem após ela. Inicialmente, a mudança na visão $V$, denotada por $\Delta V$ é inicializada por $\Delta R$. Então, a computação incremental da visão é realizada consultando as fontes de dados à esquerda de $i$, uma de cada vez. A seguir, $\Delta V$ é computada incrementalmente consultando as fontes à direita de $i$, uma por vez. Esses dois laços correspondem à computação interativa ou Sweep (razão pela qual o algoritmo tem este nome).

Em cada interação, $\Delta V$ é expandida consultando as fontes de dados $j$. A resposta $\Delta V$ é compensada no data warehouse de algum erro que aparece por causa das atualizações concorrentes $(\triangle R$, j). A deteç̧ão de atualizações concorrentes é feita verificando se a FilaMensagensAtualização ${ }^{20}$ tem atualizações da fonte $j \Delta R_{j}$ que chegaram ao data warehouse antes deste receber a resposta de $\Delta V$ da fonte de dados $j$. Se existem múltiplas atualizações interferentes encontradas

\footnotetext{
${ }^{20}$ Fila de Mensagens é uma fila que contém todas as atualizações que chegaram ao data warehouse
} 
na FilaMensagensAtualização vindas de $R_{j}$, elas podem ser agrupadas em uma única $\Delta R_{j}$ neste ponto do algoritmo. Após consultar todas as fontes de dados, exceto $i$, a mudança na visão $\Delta V$ $=R_{1} \bowtie \ldots \Delta R_{i} \bowtie R_{n}$ é retornada.

O módulo do data warehouse emprega dois processos para lidar com as mudanças na visão. O processo HistóricoAtualizações (descrito na seção 2.6.4) recebe as atualizações de várias fontes de dados sobre um canal de comunicação e anexa-os a uma fila de mensagens para futuro processamento. O outro processo, AtualizaçãoVisão (descrito na seção 2.6.4) remove uma mensagem de atualização $(\Delta R, i)$ da fila de mensagens e chama a função MudançaVisão para $\Delta R_{i}$. O processo AtualizaçãoVisão incorpora a mudança na visão $V$ e procede para remover a próxima mensagem na fila de mensagens. Se não existem novas mensagens, o processo bloqueia-se até que a fila de mensagens tenha novamente mensagens. Pressupõe-se que a visão é inicializada com o valor correto.

\title{
2.6.3 Módulo AtualizaçãoßServidorConsulta
}

\author{
CONSTANT \\ MyIndex $=i$; \\ PROCESSO EnviaAtualizacoes; \\ INICIO \\ REPITA
}

RECEBE $\Delta R$ de $R_{i}$

ENVIA( $\triangle R$, MyIndex) para Data Warehouse;

ATÉ INFINITO

FIM EnviaAtualizacoes;

PROCESSO ProcessaConsulta;

INÍCIO

REPITA

RECEBE $\Delta V$ do data warehouse

$\Delta V=$ ComputaJuncao $(\Delta V, R)$;

ENVIA $\Delta V$ para data warehouse;

ATÉ INFINITO

FIM ProcessaConsulta 
INICIO /*Inicialização*/
IniciaProcesso(EnviaAtualizacoes)
IniciaProcesso(ProcessaConsulta)
FIM AtualizacaoßServidorConsulta.

\subsubsection{Módulo data warehouse}

\section{DADOS GLOBAIS}

$V$ : Relação; /* Inicializado com a visão correta

FilaMensagensAtualização: FILA inicialmente $\emptyset$

FUNÇÃO MudancaVisao( $\triangle R$ : RELAÇÃO; AtualizaFonte: INTEIRO): RELAÇÃO

\section{VARIÁVEIS}

$\triangle V$, VisaoTemporaria: RELAÇÃO;

\section{$j$ : INTEIRO}

\section{INICIO}

$$
\triangle V=\Delta R
$$

Computa a parte esquerda do resultado são incremental para $\Delta R^{*}$ /

Para $(j=$ Atualiza $-1 ; j \geq 1 ; j-)$ faça

VisaoTemporaria $=\Delta V$;

Envie $\Delta V$ para a fonte de dados $j$;

Recebe $\Delta V$ da fonte de dados $j$;

${ }^{*}$ Remove o erro que aparece para alguma atualização concorrente se existir

Se $\exists \Delta R_{j} \in$ FilaMensagensAtualizacao, então $\Delta V=\Delta V-\Delta R_{j} \bowtie$ VisaoTemporaria;

FimIF

\section{FimPara}

Computa a parte direita do resultado da visão incremental de $\Delta R$

Para ( $j=$ AtualizaFonte $+1 ; j \leq \mathrm{n} ; j++$ ) faça

VisaoTemporaria $=\Delta V$

Envie $\Delta V$ para a fonte de dados $j$;

Recebe $\Delta V$ da fonte de dados $j$;

$/$ Remove o erro que aparece para alguma atualização concorrente se existir 
Se $\exists \Delta R_{j} \in$ FilaMensagensAtualização então $\Delta V=\Delta V-\Delta R_{j} \bowtie$ VisaoTemporaria; FimIF

FimPara

$\operatorname{RETORNO}(\Delta V)$;

FIM MudancaVisao

PROCESSO HistoricoAtualizacoes

INICIO

REPITA

RECEBE $\triangle R$ da fonte de dados $i$;

$\operatorname{ANEXE}\left(\Delta R_{i}, i\right)$ para FilaMensagensAtualizacao

ATÉ INFINITO

FIM HistoricoAtualizacoes;

PROCESSO AtualizacaoVisao

INICIO

REPITA

REMOVA $(\Delta R, i)$ da FilaMensagensAtualizacao;/*bloqueia se a fila esta vazia*/

$V=V+$ MudancaVisao $(\Delta R, i)$

ATÉ INFINITO;

FIM AtualizacaoVisao;

INICIO /*Inicia o processo no data warehouse*/

IniciaProcesso(HistoricoAtualizacoes);

IniciaProcesso(AtualizacaoVisao);

FIM data warehouse 


\subsubsection{Exemplo}

1) Sejam as relações nas fontes

$\begin{array}{lllllllll} & \mathrm{A} & \mathrm{B} & & \mathrm{C} & \mathrm{D} & & \mathrm{E} & \mathrm{F} \\ R_{1} & 1 & 3 & R_{2} & 3 & 7 & R_{3} & 5 & 6 \\ & 2 & 3 & & & & & 7 & 8\end{array}$

Seja a visão da fonte definida por $V=\left(R_{1} \stackrel{B=C}{\bowtie} R_{2} \stackrel{D=E}{\bowtie} R_{3}\right)$. Onde $\mathrm{R}_{1}, \mathrm{R}_{2}$ e $\mathrm{R}_{3}$ são três relações residentes nas fontes $X, Y, Z$ Inicialmente a visão materializada $(V M)=(7,8)[2]$.

1. O warehouse recebe a atualização $\Delta R_{2}$ de $R_{2}$.

2. O processo MudancaVisao é iniciado e, como $\Delta R_{2}=+(3,5)$ ele é removido da fila de atualizações. Como resultado da varredura à esquerda $R_{1} \bowtie+(3,5)$ é enviado para $R_{1}$.

3. $\mathrm{O}$ warehouse recebe a atualização $\Delta R_{3}$ de $\mathrm{R}_{3}$ na fonte $\mathrm{Z}$.

4. O warehouse recebe a atualização $\Delta R_{1}$ de $R_{1}$.

5. O warehouse recebe a resposta $A_{1}$ de $R_{1}=+(1,3,5)$.

6. Como existe, na fila de atualizações uma atualização que chegou da relação $R_{1}$ antes da resposta da consulta feita a ela, esta resposta deve ser compensada em relação à atualização da fila de atualizações. Então, a compensação será $-(2,3) \bowtie(3,5)=-(2,3,5)$

7. A resposta à consulta a $R_{1}$ e sua compensação são adicionadas a mudança parcial da visão $\Delta V=(1,3,5),(2,3,5)$.

8. A mudança parcial de visão $\Delta V$ é enviada para $R_{3}$ durante a varredura à direita do processo MudancaVisao em beneficio de $\Delta R_{2}$.

9. Quando a resposta é obtida de $R_{3}$, ela inclui os efeitos de $\Delta R_{3}$ e é $(1,3,5,6),(2,3,5,6)$.

10. O resultado é compensado para o termo de erro $(1,3,5)(2,3,5) \bowtie-(7,8)$ que é $\emptyset$.

11. Incorpora $\Delta \mathrm{V}$ para $\mathrm{VM}=(5,6)[2],(7,8)[2]$

12. Como a próxima mensagem de atualização é $\Delta R_{3}$, a varredura à esquerda é iniciada, então é enviada a consulta $R_{2} \bowtie-(7,8)$ para $R_{2}$. 
13. A resposta da consulta é enviada ao data warehouse e é igual a: $-(3,7,8)$.

14. A varredura à esquerda continua e a mudança parcial de visão é computada enviando a consulta $R_{1} \bowtie-(3,7,8)$ para $R_{1}$.

15. A resposta da consulta é enviada ao data warehouse e é igual a: $-(1,3,7,8)$ que reflete os efeitos de $\Delta R_{1}$.

16. A compensação local é gerada como sendo $-(2,3) \bowtie-(3,7,8) \equiv-(2,3,7,8)$.

17. A tupla de remoção é adicionada a $\Delta V$ fazendo com que $\Delta V=-(1,3,7,8)$, $-(2,3,7,8)$.

18. A visão parcial $\Delta V$ é incorporada a $\mathrm{VM}=(5,6)[2]$.

19. A próxima mensagem de atualização é $\Delta R_{1}$. A varredura à direita é iniciada, então é enviada a consulta $R_{2} \bowtie-(2,3)$ para $R_{2}$.

20. A resposta da consulta é enviada ao data warehouse e é igual a: $-(2,3,7),-(2,3,5)$

21. A varredura à direita continua, e a mudança parcial de visão é computada enviando a consulta $R_{3} \bowtie-(2,3,7),-(2,3,5)$ para $R_{3}$.

22. A resposta da consulta é enviada ao data warehouse e é igual a: $-(2,3,5,6)$ que reflete os efeitos de $\Delta R_{1}$. A resposta da consulta é incorporada a $\Delta V=-(2,3,5,6)$.

23. A visão parcial $\Delta V$ é incorporada a $\mathrm{VM}=(5,6)[1]$.

\subsection{Algoritmo Varredura Aninhado ( Nested Sweep Algorithm)}

O algoritmo Sweep incorpora o efeito de cada atualização uma por vez. Dessa forma, quando um conjunto de atualizações concorrentes ocorre, elas são tratadas seqüencialmente, incorporando o resultado de cada nova atualização no data warehouse, antes de proceder à próxima atualização. Assim, mesmo que uma atualização concorrente possa ter ocorrido, o algoritmo, conservativamente, elimina os efeitos desses termos de erro e coloca-a na fila de mensagens para ser executada posteriormente. 
Notou-se que as atualizações subseqüentes podem estar habilitadas a dividir componentes dos resultados da consulta incremental da atualização corrente. Este fato pode ser explorado adicionando consultas para as novas atualizações no topo das consultas iniciadas para a atualização corrente. Contudo, consultas resultantes de uma atualização concorrente não podem simplesmente ser ligadas em uma consulta existente antes que aquela consulta já tenha incorporado a evolução parcial das atualizações resultantes de uma atualização corrente. Essas características tratadas pelo Algoritmo de Varredura Aninhado estão descritas em [AASY97]. 


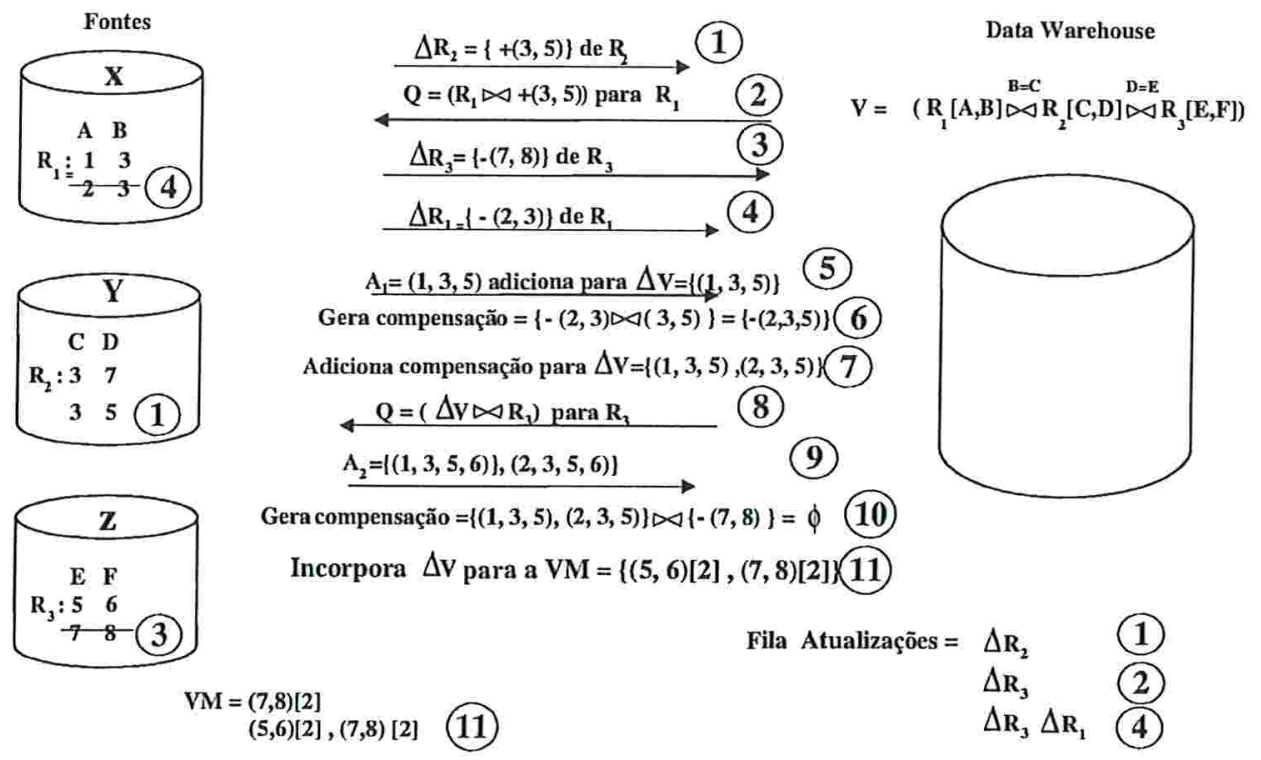

Figura 8: Algoritmo Sweep - Exemplo

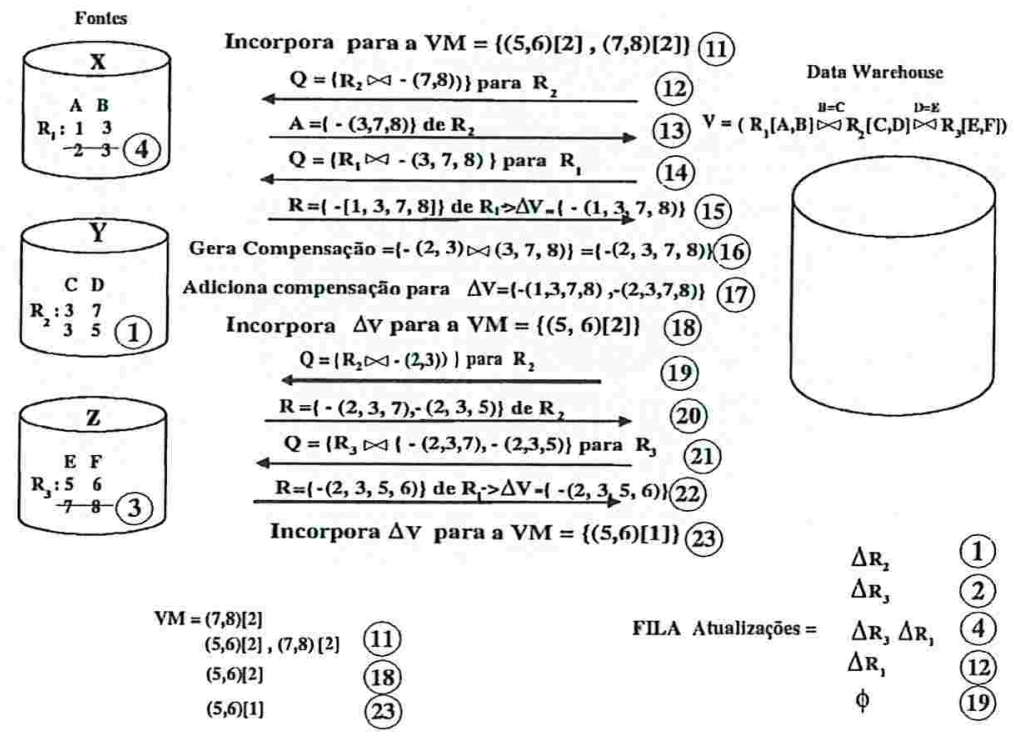

Figura 9: Algoritmo Sweep - Exemplo - Continuação 


\section{Algoritmos Assíncronos}

\subsection{Algoritmo TxnWrap}

[JCR02]

Uma das tarefas importantes do sistema gerenciador do data warehouse é manter as visões materializadas sob as mudanças das fontes, dado que atualizações freqüentes são comuns para a maioria das fontes. Entretanto, além das atualizações de dados, as mudanças de esquemas são bastante corriqueiras para as aplicações modernas.

Uma mudança de esquema pode ocorrer por inúmeras razões durante o ciclo de vida de um software: erros de projeto, redefinições durante as fases iniciais do desenvolvimento do banco de dados, adição de novas funcionalidades e também novos desenvolvimentos no domínio da aplicação, tais como novas leis de taxas e bug do ano 2000. Além disso, em ambientes distribuídos, as fontes de dados tipicamente pertencem a diferentes provedores e suas funcionalidades são independentes umas das outras. Isso implica que elas irão atualizar seus esquemas de dados autonomamente, sem qualquer conhecimento de como podem afetar as visões materializadas definidas sobre elas, causando então as chamadas anomalias de manutenção de data warehouse.

O Txnwrap descrito na seção 3.1.14 é um algoritmo de tratamento de atualizações não só dos dados, mas também do esquema de dados.

\subsubsection{Anomalias de manutenção de data warehouse}

Existem três tarefas de manutenção de data warehouse: Manutenção de Visão (MV), Sincronização de Visão (SV) e Adaptação de Visão (AV). MV mantém a visão do data warehouse sob as atualizações de dados das fontes. SV tem por função reescrever a definição de visão do data warehouse quando existem mudanças nos esquemas de dados. Por fim AV incrementalmente adapta a extensão da visão para novamente estar compatível com as recentes mudanças da definição de visão.

Se não existe concorrência entre atualizações das fontes, ou seja, se a manutenção corrente do data warehouse é completada antes que a próxima atualização ocorra, então MV incorpora cada atualização de dado enquanto SV e AV, juntos, incorporam a mudança de esquema das fontes no data warehouse. Contudo, as fontes autônomas podem submeter atualizações concorrentemente, causando as anomalias de manutenção.

Existem dois tipos de problemas de anomalias: 
- Anomalia de duplicação: aparece quando se faz uma consulta a uma fonte e uma nova atualização acontece. Essa atualização está refletida na resposta da consulta. Mais tarde, quando essa atualização for processada pelo data warehouse, essa tupla pode ser inserida na visão novamente.

- Anomalia de quebra de consulta: aparece quando se faz uma consulta a uma fonte e esta sofre uma mudança de esquema. Dessa maneira, a consulta não poderá ser mais processada e uma mensagem de erro é enviada para o data warehouse.

Uma atualização de dados concorrentes pode resultar em um resultado incorreto da consulta às fontes, enquanto uma mudança de esquema concorrente pode resultar em uma quebra de consulta, isto é uma mensagem de erro é retornada.

\subsubsection{Transação_DWMS: modelagem transacional da manutenção de data warehouse}

O processo de manutenção de data warehouse envolve leituras de fontes individuais para calcular as mudanças e atualizar a extensão do data warehouse. Enquanto isso, as fontes podem continuar a confirmar várias atualizações. Conseqüentemente, pode ocorrer concorrência entre esses dois processos. Essa anomalia de manutenção é similar à que existe nos SGBD's: pressupõese que uma junção é definida sob duas relações de fonte. Se não houver controle de concorrência, atualizações de dados concorrentes ou mudanças de esquemas nessas duas relações durante a computação do processo de junção, pode causar um problema de concorrência. Isto é similar à anomalia de manutenção de data warehouse.

Um SGBD tradicional trata esse problema com três passos:

1. Aplicando um modelo transacional para encapsular todas as operações que necessitam ser executadas atomicamente em uma transação.

2. Usando estratégias de controle de concorrência para garantir as propriedadades ACID de cada transação.

3. As propriedades ACID garantem a visão consistente do dado dentro de cada transação, portanto resolvendo o problema.

Similarmente, no contexto de data warehouse, o processo de manutenção pode ser visto como uma série de operações de leitura sobre fontes que devem ser executadas atomicamente, enquanto as 
atualizações das fontes são operações de escrita independentes. Existem conflitos entre leituras e escritas, dado que as fontes são autonômas.

\subsubsection{Transações em um ambiente de data warehouse}

Cada processo de manutenção de data warehouse é composto de duas transações:

1. Uma transação de atualização de fonte em alguma fonte de dado $D S_{i}$ é confirmada, denotada como $T_{D S_{i}}=w\left(D S_{i}\right) c\left(D S_{i}\right)$ em que $w\left(D S_{i}\right)$ significa a atualização em $D S_{i}$ e $i$ é o índice da fonte de dado, $\mathrm{c}\left(D S_{i}\right)$ denota a confirmação.

2. Uma transação de manutenção de data warehouse computa os efeitos causados pelas atualizações das fontes a fim de atualizar o data warehouse. Durante esse período, pode ser necessário enviar consultas de manutenção para investigar diferentes fontes de dados. No final, o data warehouse atualiza a extensão da visão. Isso é denotado como $T_{D W}=$ $r\left(D S_{1}\right) r\left(D S_{2}\right) \ldots r\left(D S_{n}\right) w(D W) c(D W)$, em que $r\left(D_{i}\right)$ denota leitura da fonte $\mathrm{DS}_{i}, \mathrm{w}(\mathrm{DW})$ denota escrita ou atualização do data warehouse e c(DW) denota a confirmação.

Contudo, esses dois tipos de transações não são completamente independentes, ou seja, cada transação de atualização da fonte pode disparar uma transação de manutenção de data warehouse. Além disso, essa transação de manutenção de data warehouse é necessária para enxergar um estado consistente de todas as fontes, não para conflitar com outras transações de atualização de fonte.

De qualquer maneira, as anomalias podem ocorrer. Essa observação é a base para notar-se a necessidade da criação de uma transação de alto nível que integra ambas as subtransações. As propriedades ACID desta transação de alto nível podem resolver os conflitos entres essas subtransações: transações de manutenção de data warehouse e transações de atualizações das fontes.

\subsubsection{Um modelo transacional : transação_SGDW}

É modelada uma transação de alto nível que integra tanto a transação de atualização da fonte como a sua correspondente transação de manutenção de data warehouse.

Cada transação_SGDW $T$ começa após a confirmação local, com sucesso, de uma transação de atualização de fonte de dado $T_{D S_{i}}$ e confirma após o banco de dados do data warehouse ter 
sido totalmente atualizado, isto é, a confirmação da transação de manutenção de data warehouse $T_{D W}$. Então isso é denotado por:

$$
" T=T_{D S_{i}} T_{D W}=w\left(D S_{i}\right) c\left(D S_{i}\right) r\left(D S_{1}\right) r\left(D S_{2}\right) \ldots r\left(D S_{n}\right) w(D W) c(D W) " .
$$

Com o conceito de transação_SGDW, a manutenção anômala de data warehouse pode ser reformulada como o bem conhecido problema de leitura de dados incoerentes pela transação. Com uma solução apropriada de controle de concorrência para garantir as propriedades ACID de tal transação_SGDW, os conflitos entre as transações_SGDW, podem naturalmente ser resolvidos.

\subsubsection{Escalonamento de transações_SGDW}

Dois tipos de escalonadores de transação_SGDW são possíveis: seqüencial e paralelo.

Um escalonador seqüencial não permite que outra transação_SGDW seja processada até que a corrente tenha sido completada. A maioria dos algoritmos de manutenção emprega este escalonamento seqüencial para manutenção de data warehouse mesmo que eles não utilizem a terminologia de transações.

O escalonador paralelo é mais complexo, haja vista que a falta de ordem do processo de manutenção de data warehouse introduz conflitos adicionais.

\subsubsection{Conflitos entre transações_SGDW}

Existem três operações básicas de leitura e escrita dentro de uma transação_SGDW chamadas de $w D S_{i}, r D S_{i}$ e $w(D W)$. Também há três tipos de conflitos entre essas operações. Primeiro alguma operação de escrita $w_{1} D S_{i}$ em uma transação_SGDW $T_{1}$ conflita com $w_{2} D S_{i}$ em outra transação_SGDW $T_{2}$. Segundo acontece quando alguma operação de escrita $w_{1}(D W)$ em uma transação_SGDW $T_{1}$ conflita com $w_{2}(D w)$ em outra transação_SGDW $T_{2}$. É claro que tais conflitos de escrita com escrita podem ser resolvidos pelo gerenciador local de dados tanto das fontes quanto do data warehouse. O terceiro conflito é do tipo leitura-escrita, tal que $r D S_{i}$ em uma transação_SGDW $T_{1}$ pode ler algum resultado inconsistente de consulta escrito por $w D S_{i}$ em outra transação_SGDW $T_{2}$.

Lema 1 [JCR02] A anomalia de manutenção de data warehouse aparece durante os conflitos de leitura-escrita da transação_SGDW.

\subsubsection{Serialização das transações_SGDW}

O lema 1, cuja prova esta em [JCR02] mostra uma estratégia para se resolver os conflitos, 
ou seja deve-se garantir a serialização das transações_SGDW.

Teorema 1 [JCR02] Uma história de transações_SGDW $S$ é seriável se é equivalente a algum escalonamento serial S' de algumas transações_SGDW.

O escalonamento serial das transações_SGDW $S^{\prime}$ pressuõe que a atualização da fonte e o processo de manutenção ocorrem um após o outro. Nesse caso, a atualização da fonte e o processo de manutenção não conflitam um com o outro e, conseqüentemente a anomalia de manutençao de data warehouse não ocorre.

\subsubsection{Algoritmo de controle de concorrência de multiVersão para transa- ções_SGDW}

Para garantir a seriação de transações tradicionais, geralmente dois tipos de algoritmos de controle de concorrência são usados: baseados em bloqueio e baseados em multiversões.

$\mathrm{O}$ algoritmo tradicional baseado em bloqueio é descrito em [BHG87]. Ele é muito restritivo para o escalonador de Transações_SGDW, pois se sabe que uma Transação_SGDW irá ler sobre todas as fontes, então um bloqueio de leitura seria necessário sobre todas elas. Contudo, as fontes são autônomas no ambiente de data warehouse e não são permitidos bloqueios de agentes externos as fontes.

No algoritmo de controle de concorrência multiversão tradicional [BHG87], a transação de manutenção do data warehouse irá ler uma versão mais antiga do que está sendo escrita pelas fontes de dados e, dessa maneira previnindo conflitos. Esses algoritmos de multiversão podem ser divididos em duas categorias: os de versão finita, como mostrado em [QW97]; e os de versão ilimitada como mostrado em [AS89]. Nos algoritmos de multiversão ilimitada, as fontes de dados podem sempre criar uma nova versão dos dados a serem escritos e as transações de manutenção do data warehouse podem procurar as versões que elas necessitam a qualquer instante. Nenhum bloqueio entre operações de escrita e leitura irá ocorrer.

Com base no funcionamento dos algoritmos citados, foi escolhido um algoritmo de multiversão ilimitada para o desenvolvimento do data warehouse. Primeiro é necessário que a versão que a transação de manutenção necessita não se expire antes que o processo de manutenção tenha sido completado, caso contrário o data warehouse pode ficar inconsistente. Em segundo lugar a atualização da fonte não deve ser sincronizada com o processo de manutenção DW. Por esta razão, o algoritmo de multiversão ilimitada foi escolhido. Note que como as Transações_SGDW irão ler uma versão crescente e monotônica dos dados em vez de alguma antiga randômica, a 
limpeza de versão pode ser eficientemente realizada.

Desta forma pode-se criar um algoritmo de multiversão ilimitado, chamado ShadowWrap. A principal idéia desse algoritmo é estender as funcionalidades dos wrappers além da comunicação entre fontes e o data warehouse, ou seja, o wrapper é responsável por armazenar as versões geradas durante as atualizações nas fontes e responder a alguma consulta de manutenção do $D W$ usando a informação versionada.

\subsubsection{Materialização dos wrappers}

O wrapper de cada fonte é estendido para conter relações com versões das fontes de dados, chamadas de relaçốes wrappers. Uma simples replicação total dos dados das fontes para os wrappers pode garantir que o wrapper responderá a uma consulta de manutenção sem nenhum outro acesso à fonte. Esse fato pode ser melhorado utilizando as definições da visão para filtrar dados desnecessários.

São também adicionados dois novos atributos em cada relação wrapper: $V_{-}$Start e $V_{-}$End para denotar o tempo de vida de cada tupla. $V_{-}$Start denota a versão inicial da tupla (por inserção), e $V_{-}$End denota a versão em que a tupla se finaliza (por remoção).

As tuplas na relação wrapper são inicializadas com $V_{-}$Start $=0$ e $V_{-}$End $=\infty$. Isso garante que todas as tuplas iniciais serão visíveis para todas as transações_SGDW. É criada uma metarelação no wrapper para o versionamento do metadado da fonte. Essa metarelação contém seis atributos: Rel, Attr, Rel', Attr',V_Start, $V_{-}$End. O par de atributos Rel, Attr descreve o metadado da fonte. O par de atributos Rel', Attr' indica o novo nome de um atributo em particular ou de uma relação. O par de atributos $V_{-}$Start, $V_{-}$End denota o ciclo de vida dos atributos, isto é, o número da versão em que eles foram criados, renomeados ou removidos. A seguir temos um exemplo de uma relação wrapper.

Wrapper para uma fonte Relação F'

\begin{tabular}{|c|c|c|c|c|c|}
\hline Nome & Idade & NumeroVoo & Destino & V_Start & V_End \\
\hline Tom & 17 & AA4399 & Asia & 0 & $\infty$ \\
\hline
\end{tabular}


MetaRelação

\begin{tabular}{|c|c|c|c|c|c|}
\hline Rel & Attr & Rel' & Attr' & V_Start & V_End \\
\hline F' $^{\prime}$ & Nome & - & - & 0 & $\infty$ \\
\hline F' $^{\prime}$ & Idade & - & - & 0 & $\infty$ \\
\hline$F^{\prime}$ & NumeroVoo & - & - & 0 & $\infty$ \\
\hline F' $^{\prime}$ & Destino & - & - & 0 & $\infty$ \\
\hline
\end{tabular}

\subsubsection{Gerenciamento de versão}

Basicamente existem três classes de operações de versão que o wrapper pode realizar:

- A criação de versões sempre que uma atualização é enviada por uma fonte;

- A leitura de uma versão apropriada para responder cada consulta de manutenção.

- A limpeza de qualquer versão que não for mais necessária para uma transação_SGDW.

\subsubsection{Criação de versão no wrapper}

As atualizações enviadas pelas fontes podem ser categorizadas como atualizações de dados (inserção, remoção e alteração), ou mudança de esquemas(inserir, remover, renomear um atributo ou criar, remover e renomear uma relação).

Para criar versões, cada transação_SGDW será associada a um número de versão baseado na sua transação de atualização de fonte correspondente. As criações de versão correspodente são listadas a seguir:

1. Remover uma tupla $t$ : atualize $V_{-}$End para i(número da transação).

2. Inserir uma tupla $t$ : insere a tupla, atualize $V_{-}$Start para i, atualize $V_{-}$End para $\infty$

3. Alterar uma tupla $t$ : trate como uma remoção seguida de uma inserção.

4. Remover um atributo: atualize o atributo $V_{-} E n d$ para $i$ na metarelação.

5. Inserir um atributo: insira o atributo na metarelação, com $V_{-}$Start $=$i e $V_{-}$End $=\infty$ 
6. Renomear um atributo: na met relação atualize os atributos Rel', Attr' do atributo antigo para seu novo nome, atualize $V_{-}$End para $i$. Então adicione o atributo renomeado para a metarelação.

7. Remover uma tabela: trate como uma remoção de todos os atributos

8. Adicionar uma tabela: adicione todos os atributos para a metarelação.

9. Renomear uma tabela : método similar a renomeação de um atributo, mas realizado sobre todos os atributos.

\subsubsection{Leitura de versão no wrapper}

A leitura de versão acontece quando uma transação_SGDW quer consultar uma fonte. Em vez de serem processadas pelas fontes, as consultas são reescritas pelo wrapper e executadas lendo a versão apropriada do esquema do wrapper e suas relações.

A transação_SGDW necessita ver um estado consistente de todas as fontes. Então, as versões criadas posteriormente, devem ser invisíveis para essa transação_SGDW. Para garantir isso, a consulta de manutenção original é reescrita colocando em seus argumentos as condições de versão "ANDV_Start $\leq i$ AND $i<V_{-} E n d "$. Essa nova consulta será executada na relação wrapper e não na relação da fonte atual. Define-se $i$ como o número da versão desta transação_SGDW.

\subsubsection{Limpeza de versão no wrapper}

É necessário limpar as versões que não são mais necessárias para as transações_SGDW. Para um escalonador serial essa tarefa é simples. Após a completa execução de uma transação_SGDW com número de versão $i$, todos os dados com V_End menor que $i$ serão removidos desde que não sejam mais visíveis nem requeridos por alguma transação de manutenção. Para garantir esse fato, na metarelação, será executada uma atualização como "delete * from meta-relacao where $V_{-} E n d \leq i "$ e a execução das operações correspondentes nestes atributos na relação wrapper. Então também são removidas as tuplas na relação wrapper com $V_{-}$End $\leq i$.

\subsubsection{TxnWrap : um algoritmo multiversão para manutenção de DW}

1. Primeiro o wrapper inicializa seus esquemas e relações 
2. Uma vez que uma determinada fonte confirma uma transação de atualização local e envia esta atualização para o wrapper, este pega uma identificação de versão de transação_SGDW única e global e a usa para criar as versões. Após isso ele notifica o warehouse sobre as atualizações.

3. Quando o wrapper recebe uma consulta de manutenção do $S G D W$, ele reescreve a consulta de manutenção de acordo com a correspondente identificação da transação_ $S G D W$ e a executa sobre as relações-wrapper.

4. Uma vez que uma transação_SGDW é confirmada no data warehouse, a limpeza de versão começa. Essa limpeza pode ser feita por um processo ativo em memória. 


\subsection{Algoritmo de propagação de rolagem}

\section{[SBCL00]}

A atualização on-line ${ }^{21}$ é bastante desejada em vários casos. Porém as aplicações on-line devem estar atentas para deixar a visão materializada em um estado intermediário de consistência transacional. A menos que as tabelas sejam muito pequenas ou as mudanças muito rápidas, é necessário atualizar a visão incrementalmente. Em muitos casos não é possível, ou necessário, manter um processo de atualização totalmente on-line. Dessa maneira pode-se aplicar uma técnica ortogal mostrada em [CGL $\left.{ }^{+} 96\right]$. Essa técnica divide a computação de atualização em duas fases: a fase de propagação e a fase de aplicação.

Durante a fase de propagação, as mudanças de visão são computadas e armazenadas. Mais tarde, durante a fase de aplicação, as atualizações armazenadas são usadas para atualizar o data warehouse. O algoritmo descrito em [SBCL00] utiliza a técnica de atualização de visão em duas fases. Ele é chamado de rolagem da propagação da junção (rolling join propagation) e endereça tanto o problema de transações longas como o problema de sincronização de atualizações. Para esse algoritmo existem três características significativas:

1. A propagação da visão delta (visão intermediária) é assíncrona;

2. A propagação da visão delta é tratada como um processo contínuo (por meio de uma série de pequenas transações ao invés de uma única transação longa;

3. As mudanças armazenadas na visão delta são rotuladas para indicar quando elas podem ser aplicadas à visão. Rótulos de tempo facilitam o controle do tamanho das transações de propagação e permitem manutenção incremental (point-in-time).

A técnica de rolagem da propagação usa processos separados para propagação e aplicação. Os dois processos são completamente independentes. Cada processo ou ambos pode ser suspenso durante períodos de alta carga no sistema, ou por outras razões. Em determinado tempo, a tabela visão delta contém uma completa cobertura rotulada do intervalo da visão corrente materializada até a "marca-d'gua"22 mais alta na tabela de visão delta. Isso significa que a visão delta pode conter tuplas adicionais como mudanças parcialmente computadas que foram geradas da marca dágua mais alta até o tempo atual. O processo de aplicação pode distinguir essas tuplas usando

\footnotetext{
${ }^{21}$ Refere-se ao fato de uma atualização confirmada em uma fonte de dados ser aplicada ao data warehouse pouco depois que ocorre nas fontes de dados.

${ }^{22}$ Marca que indica as últimas tuplas totalmente validadas e prontas para serem aplicadas a VM
} 
seus rótulos de tempo. Por causa do rótulo de tempo nas tuplas, o processo de aplicação pode usar a visão delta para rolar a visão materializada para algum tempo próximo ou igual à marca d'água.

\subsubsection{Definições}

- Uma tabela delta (provavelmente uma visão) descreve mudanças feitas em uma tabela das relações fonte.

- As tabelas das fontes serão chamadas de tabelas base.

- Se $\mathrm{R}$ é uma tabela base $\Delta \mathrm{R}$ será usado para descrever as mudanças ocorridas em $\mathrm{R}$ (tabela delta).

- $\Delta \mathrm{R}$ tem os mesmos atributos de $\mathrm{R}$ mais outros dois: count e timestamp.

- Um valor de contador de n+ é usado para representar a inserção de n cópias da tupla associada.

- Um valor de contador de n- é usado para representar a remoção de n cópias da tupla associada.

- Timestamp representa o tempo de inserção e remoção.

- Para manter uma notação uniforme, cada tabela base é considerada como tendo os atributos count e timestamp implícitos. O valor implícito de count para cada tupla é +1 . O valor implícito de timestamp é nulo. Esses atributos existem apenas por conveniência notacional e não são representados explicitamente nas tabelas base.

- O algoritmo assume os itens 1, 2, 3, 4 descritos na seção 2.1.1.

- A história transacional é assumida como sendo seriável, e a ordem da confirmação das transações é assumida como sendo consistente com a ordem de seriação.

- Nas tabelas delta, o valor dos rótulos de tempo das tuplas é o tempo de confirmação da transação que inseriu ou que mais recentemente atualizou a tupla.

- A operação $\sigma_{a, b}$ seleciona todas as tuplas tendo o atributo timestamp maior que $t_{a}$ e menor ou igual a $t_{b}$. 
- A notação $R_{a, b}$ é uma abreviação de $\sigma_{a, b}(\Delta R)$.

- O algoritmo computa a visão delta usando consultas de propagação. Em geral, a visão delta será a união dos resultados de uma ou mais consultas de propagação. As consultas de propagação para uma visão $\mathrm{V}$ têm a mesma forma da definição da visão com algumas tabelas base substituídas por suas tabelas delta correspodentes.

- Consultas de propagação produzem tabelas delta. Os atributos timestamp e count para estas tabelas são computados dos timestamp e count das tabelas nas quais a consulta foi definida. O count de uma tupla da visão delta é o produto dos atributos count das tuplas que ela foi derivada. O timestamp de uma tupla da visão delta é o mínimo dos timestamp das tuplas das quais ela foi derivada.

- A notação $Q^{V}[i]$ é usada para representar a $i$-ésima relação na consulta de propagação $Q^{V}$ para a visão $V \cdot Q^{V}[i]$ é também $\mathrm{R}^{i}$ ou $\mathrm{R}_{x, y}^{i}$, dependendo de onde $\mathrm{R}^{i}$ tenha sido substituída por sua tabela delta na consulta.

- A notação $Q_{b}^{V}$ é usada para representar o resultado de computar uma consulta $Q^{V}$ no tempo $t_{b}$.

- O resultado de consultas que envolvem apenas tabelas delta são realizáveis em algum tempo após o final do último intervalo de tempo das tabela delta na consulta.

\subsubsection{Propagação assíncrona}

O objetivo da propagação assíncrona é quebrar a computação da propagação em pequenos pedaços, cada um sendo executado após o intervalo de propagação. A propagaçao assíncrona pode ser alcançada usando compensação.

Considere o resultado da consulta $Q_{b}^{V}=\mathrm{R}_{a, b}^{1} \mathrm{R}_{b}^{2} \mathrm{R}_{b}^{3}$. Suponha que o resultado da consulta é avaliado em algum tempo depois de $\mathrm{t}_{c}$, em vez $\mathrm{t}_{b}$, resultando em $Q_{c}^{V}=\mathrm{R}_{a, b}^{1} \mathrm{R}_{c}^{2} \mathrm{R}_{c}^{3}$. Como $\mathrm{R}^{2}$ e $\mathrm{R}^{3}$ podem estar envolvidos entre $\mathrm{t}_{b}$ e $\mathrm{t}_{c}, Q_{b}^{V}$ e $Q_{c}^{V}$ no geral não serão iguais. Contudo, esse problema poderá ser resolvido pela compensação de algum erro causado pelas mudanças para $R^{2}$ e $R^{3}$ feitas entre os tempos $t_{b}$ e $t_{c}$.

Compensação envolve adicionar mudanças extras para a visão delta. Por exemplo, se $Q_{c}^{V}$ inclui tuplas extras de inserção que não estão em $Q_{b}^{V}$, elas são compensadas pela adição de remoções correspodentes para a visão delta. A diferençâ entre $Q_{b}^{V}$ e $Q_{c}^{V}$ é $Q_{b, c}^{V}$. Isso significa 
que a consulta $Q^{V}$ pode ser tratada como uma definição da visão e suas mudanças incrementais de $t_{b}$ para $t_{c}$ podem ser calculadas. A compensação requirida para corrigir essa diferença é exatamente $-Q_{b, c}^{V}$ desde que cada inserção em $Q_{b, c}^{V}$ torne-se uma remoção em - $Q_{b, c}^{V}$ e as inserções sejam correspondentes às remoções. Como $Q^{V}$ tem a mesmo forma da visão $\mathrm{V}, Q_{b, c}^{V}$ e também - $Q_{b, c}^{V}$ podem ser calculadas usando o mesmo método para calcular a visão delta mostrado em $\left[\mathrm{CGL}^{+}\right.$96].

Considere o seguinte exemplo para $V=R^{1} R^{2}$. A visão delta pode ser calculada como:

$$
V_{a, b}=R_{a, b}^{1} R_{b}^{2}+R_{a}^{1} R_{a, b}^{2}
$$

A primeira consulta pode ser movida para o tempo $t_{c}$ e a segunda para o tempo $t_{d}$.A compensação pode ser adicionada para cada consulta para corrigir algum erro introduzido pelos movimentos no tempo. Isso nos leva a:

$$
V_{a, b}=R_{a, b}^{1} R_{c}^{2}-\left(\mathbf{R}_{\mathrm{a}, \mathrm{b}}^{1} \mathbf{R}^{2}\right)_{\mathrm{b}, \mathrm{c}}+\mathbf{R}_{\mathrm{d}}^{1} \mathbf{R}_{\mathrm{a}, \mathrm{b}}^{2}-\left(\mathbf{R}^{1} \mathbf{R}_{\mathrm{a}, \mathrm{b}}^{2}\right)_{\mathrm{a}, \mathrm{d}}
$$

A consultas de compensação são mostradas em negrito. A primeira compensação pode ser calculada por meio de uma nova aplicação do método em [CGL $\left.{ }^{+} 96\right]$ :

$$
\left(R_{a, b}^{1} R^{2}\right)_{b, c}=\left(R_{a, b}^{1}\right)_{b, c} R_{c}^{2}+\left(R_{a, b}^{1}\right)_{b} R_{b, c}^{2}
$$

Como $R^{1}$ não está envolvida, $\left(R_{a, b}^{1}\right)_{b, c}$ é vazio, e a expressão de compensação pode ser simplificada para:

$$
\left(R_{a, b}^{1} R^{2}\right)_{b, c}=R_{a, b}^{1} R_{b, c}^{2}
$$

Usando a mesma técnica, o termo de compensação $R^{1} R^{2} a, b$ pode ser encontrado em $R_{a, d}^{1} R^{2} a, b$, o que nos dá o seguinte cálculo de sincronização de $V_{a, b}$ : 


$$
V_{a, b}=R_{a, b}^{1} R_{c}^{2}-R_{a, b}^{1} R_{b, c}^{2}+R_{d}^{1} R_{a, b}^{2}-R_{a, d}^{1} R_{a, b}^{2}
$$

O algoritmo a seguir é um algoritmo de propagação assíncrona chamado ComputeDelta que generaliza a técnica de $\left[\mathrm{CGL}^{+} 96\right]$ para visões definidas sobre $n$ relações base. O algoritmo tem uma consulta de propagação $Q$ de $n$ maneiras, um vetor rotulado $t_{\text {old }}$ e um novo tempo $t_{\text {new }}$. Ele computa $Q_{\text {old,new }}$, isto é, o delta para $Q$ de $t_{\text {old }}$ até tempo $t_{\text {new }}$. Ele pode ser usado para computar a visão delta $V_{a, b}$ setando $Q=V, t_{\text {old }}=[a, a, \ldots, a]$ e $t_{n e w}=t_{b}$. ComputeDelta usa a função Execute para executar as consultas. Cada chamada a Execute é feita para inserir seus resultados na tabela visão delta na qual está sendo acumulada. Cada chamada para Execute faz sua consulta como uma transação separada e retorna o tempo de confirmação dessa transação.

\subsubsection{Rótulos de tempo}

O tamanho dos intervalos de propagação determina o custo das consultas de propagação. A escolha de pequenos intervalos, leva a muitas pequenas consultas de propagação, e a escolha de intervalos longos leva a poucas e longas consultas. Então, o intervalo age como um parâmetro que pode ser ajustado para balancear a sobrecarga da execução da consulta sobre a contenção de dados.

Adicionalmente, o intervalo de propagação determina o ponto no tempo para o qual a visão materializada poderá ser rolada ("atualizada"). Se a visão materializada no tempo $t_{a}$ e a visão delta $V_{a, b}$ são propagadas, então é possível rolar a visão do tempo $t_{a}$ para $t_{b}$. Porém, não é possível rolar a visão para nenhum tempo $t_{b^{\prime}}$, em que $t_{a}<t_{b^{\prime}}<t_{b}$.

Idealmente, a propagação e o processo de aplicação devem ser tão independentes quanto possível. A escolha de um intervalo de propagação pode ser feita independente de um processo de aplicação pela geração de um rótulo-de-tempo para cada tupla propagada para a visão delta. O rótulo de tempo indica o tempo de confirmação da transação que gerou a mudança. Para rolar a visão de um tempo $t_{a}$ para $t_{b^{\prime}}$, o processo de aplicação seleciona as tuplas da visão delta com rótulo-de-tempo nesse intervalo e aplica essas tuplas na visão materializada. Com essa mudança, o processo de propagação pode ser feito independente da aplicação. O intervalo de propagação pode ser usado somente como um parâmetro de ajuste do processo de propagação, permitindo que o tamanho das consultas de propagação seja controlado. O processo de propagação pode ser 
implementado como um laço que continuamente gera tuplas na visão delta com rótulos de tempo para sucessivos intervalos de tempos passados. O processo de Propagação é mostrado a seguir:

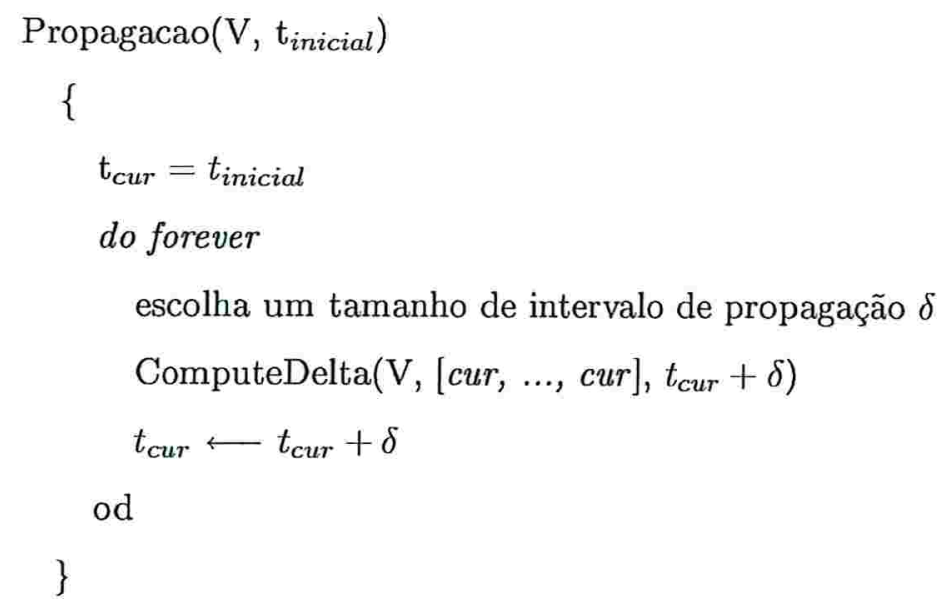

Propagação gera uma visão delta começando em um tempo específico $t_{\text {inicial }}$. A variável $t_{c u r}$ pega a marca d'gua mais alta da visão delta. Na conclusão de cada interação de Propagação, a visão delta é ajustada para o intervalo de $t_{\text {inicial }}$ a $t_{\text {cur }}$.

Cada tabela base delta inclui um atributo timestamp para indicar os tempos de confirmação das mudanças que ela armazena. Como visto na seção 3.2.1, o atributo timestamp de uma tupla da visão delta é o mínimo dos atributos timestamp das tuplas que fizeram a junção para produzi-la.

\subsubsection{Propagação de Rolagem}

O algoritmo de propagação de rolagem junto com os rótulos de tempo endereçam o problema de manutenção de visão incremental. O algoritmo de propagação de rolagem é um refinamento de propagação. A principal diferença entre os dois é que o algoritmo de propagação de rolagem provê maior controle sobre o tamanho das consultas de propagação.

O procedimento ComputeDelta no qual propagação é baseado provê um parâmetro ajustável: o tamanho do intervalo de propagação. Todas as consultas enviadas usam o mesmo intervalo. Contudo, em muitos casos, as tabelas base serão atualizadas em taxas diferentes. Dessa maneira, 
o algoritmo de propagação de rolagem permite intervalos diferentes para cada tabela base. Então ele provê $n$ parâmetros ajustáveis independentes em vez de um.

O algoritmo de propagação de rolagem tende a gerar menos consultas com grandes propagações do que o propagação. Apesar de ambos os algoritmos serem baseados no procedimento ComputeDelta, a propagação de rolagem diferencia as compensações de algumas consultas enviadas e as combina com compensações para consultas que aparecerão futuramente. Como resultado, ele faz menos chamadas para ComputeDelta do que Propagação. A descrição completa do algoritmo de propagação e sua forma algorítmica pode ser encontrada em [SBCL00]. 


\subsection{Resumo dos Algoritmos}

\begin{tabular}{|c|c|c|c|c|c|}
\hline Algoritmo & Arquitetura & Consistencia & $\begin{array}{l}\text { Custo da mensagem } \\
\text { por atualização } \\
\text { (n - \#fontes) }\end{array}$ & $\begin{array}{c}\text { Caracteristicas } \\
\text { especificas }\end{array}$ & $\begin{array}{l}\text { Tipo de } \\
\text { atualização* }\end{array}$ \\
\hline$E C A$ & Centralizada & Forte & $O(1)$ & $\begin{array}{l}\text { Compensação remota } \\
\text { Mensagem de tamanho quadrático } \\
\text { Requere estado quiescente }\end{array}$ & síncrona \\
\hline Strobe & Distriburda & Forte & $O(n)$ & $\begin{array}{l}\text { Hipótese de chave única } \\
\text { Requere estado quiescente }\end{array}$ & síncrona \\
\hline C-Strabe & Distriburda & Completa & $O(n !)$ & $\begin{array}{l}\text { Hipótese de chave única } \\
\text { Não-escalável }\end{array}$ & síncrona \\
\hline Sweep & Distribufda & Completa & $\mathrm{O}(\mathrm{n})$ & Compensação local & síncrona \\
\hline $\begin{array}{l}\text { Nested } \\
\text { Sweep }\end{array}$ & Distriburda & Forte & $O(n)$ & $\begin{array}{l}\text { Compensação local } \\
\text { Requere nāo-interferência }\end{array}$ & síncrona \\
\hline Tan Wrap & Distriburda & Completa & $O(n)$ & $\begin{array}{l}\text { Relaçōes nos wrappers para armazenar } \\
\text { atualizaçōes das fontes } \\
\text { Não requer consultas compensatorias } \\
\text { Trata mudança de esquemas das fontes }\end{array}$ & assíncrona \\
\hline
\end{tabular}

Tabela 1: Tabela de comparação das complexidades dos algoritmos

O algoritmo Sweep garante consistência completa, então todas as consultas executadas no data warehouse são garantia de uma visão consistente na base de dados distribuída. A compensação dos erros é completamente localizada no data warehouse, ao contrário de outros algoritmos. Como conseqüência, o custo de computar a visão por atualização é linear no número de mensagens, ou seja, apenas (n - 1) mensagens são necessárias quando se possui $n$ fontes.

Algoritmos como ECA, Strobe e C-Strobe terminam totalmente de executar uma consulta antes de fazer qualquer compensação. Consequentemente, todas as atualizações recebidas entre o início da consulta e ela ser completamente respondida, são consideradas atualizações concorrentes. Por causa desse fato, teremos as complexidades dos algoritmos em relação ao número de mensagens de $\mathrm{O}(1), \mathrm{O}(\mathrm{n})$ e $\mathrm{O}(\mathrm{n}-1)$ ! no pior caso. 
Apesar de o Strobe poder ser mais eficiente, visto que adiciona à mudança da visão várias atualizações, ele pode não terminar se não existir um estado quiescente do data warehouse.

O ECA não pode ser diretamente comparado com os demais algoritmos por se tratar de ambiente centralizado, contudo o número de mensagens do $E C A$ cresce quadraticamente em termo do número de atualizações concorrentes. Um outro fator a ser considerado é que Strobe e o C-STrobe são restritivos, pois ambos assumem que a função da visão inclui os atributos-chave de todas as relações base da visão.

O Algoritmo Nested Sweep é uma otimização do algoritmo Sweep, sua complexidade de mensagens é limitada pelo Algoritmo Sweep e também é linear. Quando existem muitas atualizações, o Nested Sweep constrói a mudança de visão coletivamente e o custo das mensagens é amortizado para as múltiplas atualizações. Uma outra vantagem dos algoritmos Sweep e Nested Sweep é que eles não requerem estado de repouso, porém exigem que as atualizações não sejam uma seqüência com atualizações que interferem uma na outra, pois, nesse caso, o algoritmo oscilaria entre as duas relações fontes até que a seqüência alternada ou as atualizações interferentes dessas relações fontes sejam quebradas.

$\mathrm{O}$ algoritmo ThxWrap requer que cada wrapper mantenha uma relação para armazenar as mudanças das fontes. Em muitos casos haverá necessidade de grande espaço em disco. Por outro lado, por causa dos rótulos em cada atualização ele garantirá consistência completa pois repassará cada estado da fonte para o warehouse e não causará impacto sobre as fontes de dados que continuarão executando seu trabalho. Além do mais, o custo de manutenção para cada atualização é fixo, ao contrário dos demais algoritmos que têm seu custo acrescido de acordo com o número de atualizações concorrentes. 


\section{Sugestão de um algoritmo assíncrono para atualiza- ções de dados}

\subsection{Parâmetros que interferem nas atualizações}

Um fator que foi decisivo para a escolha de algoritmos assíncronos foi um conjunto de alguns parâmetros identificados que são relevantes para qualquer tipo de algoritmo de atualização de dados em data warehouse. Alguns desses parâmetros são descritos a seguir:

1. Quantidade de comunicação: Mede a quantidade de mensagens trocadas entre o data warehouse e as fontes de dados para que uma atualização possa ser incorporada no data warehouse.

2. Volume de dados: Mede o tamanho das mensagens que são transportados entre as fontes de dados e o data warehouse.

3. Tipo de atualização: Mede o grau de atualizações que os algoritmos se propõem a manter. Podem ser síncrona ou assíncrona.

4. Defasagem de atualizações: Mede o grau de defasagem entre o data warehouse e o ambiente de dados operacional, ou seja, em que medida o data warehouse está realmente atualizado com as fontes de dados.

5. Grau de concorrência de dados no ambiente de dados operacional e no data warehouse: Mede o grau de concorrência existente entre o processo de consulta no data warehouse e a atualização dos dados.

6. Grau de agregação dos dados: Mede qual a complexidade de agregação dos dados que são transportados das fontes de dados para o data warehouse.

Por meio dos parâmetros, detecta-se inicialmente o tempo que uma atualização gasta para ser incorporada nas visões do data warehouse. Esse tempo está vinculado a três parâmetros principais: grau de concorrência de dados no banco de dados operacional e no data warehouse, grau de agregação de dados e quantidade de comunicação. Dessa maneira, pode-se expressar o tempo total gasto para uma atualização ser incorporada no data warehouse como uma função: 
em que :

C: grau de concorrência de dados

Agr: grau de agregação dos dados

Qm: quantidade de mensagens trocadas

Esses três parâmetros (C, Agr, Qm) impactam o tempo de atualização $\Delta \mathrm{t}$, pois:

- Quanto maior a concorrência no data warehouse e nas fontes de dados, mais uma atualização demorará a ser propagada, pois esta concorre com todos os processos que estão executando localmente. Havendo maior concorrência pode-se acabar prejudicando também os processos locais, havendo perda de desempenho. Como alguns algoritmos exigem estado quiescente, pode-se não chegar a um estado atualizado.

- Quanto maior o grau de agregação dos dados a serem incorporados no data warehouse, mais tempo se gastará para sua obtenção, pois deverão ser feitas muitas junções para obter esses dados.

- Quanto maior o número de mensagens a serem enviadas por uma atualização, mais tempo se gastará esperando a total recepção de suas respostas. Além disso, um maior número de mensagens pode fazer com que o meio de comunicação se torne lento e atrase ainda mais as atualizações.

Através dos parâmetros descritos acima, mostra-se mais clara a necessidade da proposta de um algoritmo assíncrono que minimize os efeitos acarretados pela atualização síncrona. A alternativa proposta objetiva reduzir o problema de concorrência de dados nas fontes e no warehouse, pois os prâmetros seriam responsáveis por determinar o momento da carga.

\subsection{Proposição de um algoritmo assíncrono}

O algoritmo chamado de algoritmo de log com nível zero de agregação de dados é outra contribuição importante deste trabalho. Tal algoritmo transforma as atualizações confirmadas das fontes de dados em informações de log para serem aplicadas no warehouse. Para realizar esse processo, ele se utiliza de uma estrutura de-para, que faz o mapeamento dos dados do banco de dados 
operacional no data warehouse e de um modelo de armazenamento diferenciado no warehouse, chamado de nível zero de agregação, onde os dados não estão sumariados. Tal pressuposto de nível zero de agregação, se faz necessário em função da eliminação das consultas intermediárias às fontes para atualizações de dados. A eliminação das consultas só é possível devido a propagação dos dados existentes no ambiente operacional sem alguma junção ou agregação para a geração dos mesmos dados no ambiente analítico. Como mencionado no capítulo 2 as consultas intermediárias que retornam as fontes são elementos de grande ineficiência para os respectivos algortimos. Portanto a utilização do nível zero de agregação, simplifica nossa proposta de algoritmo para propagação das atualizações em questão. Maiores informações sobre nível zero de agregação podem ser obtidas em [Ita02].

\subsubsection{Wrappers}

Quando ocorre uma transação(atualização) nas fontes de dados, após sua confirmação, ela é enviada para os wrappers através de triggers nas relações das fontes. Os wrappers, neste algoritmo, quando recebem as transações(atualizações) copiam-nas para um log local dentro dos próprios wrappers. São consideradas três tipos de atualizações que ocorrem nas fontes: inserção, remoção e alteração que, como já mostrado em outros trabalhos, será tratada como uma remoção seguida de uma inserção. A informação a ser gravada no log local tem a forma geral mostrada na tabela 2 :

\begin{tabular}{|l|l|l|l} 
Fonte & Rel & Atrib1, Val ant1, Val atual1, ... , AtribN, Val antN, Val atualN \\
\hline
\end{tabular}

Tabela 2: Formato geral de arquivo de log

em que:

- Fonte é o nome da fonte de dados

- Rel é o nome da relação dentro da fonte de dados

- Atrib1 é o nome do primeiro atributo na relação

- Val ant1 é o valor anterior do primeiro atributo na relação

- Val atual1 é o novo valor do primeiro atributo na relação 
- AtribN é o nome do último atributo na relação

- Val antN é o valor anterior do último atributo na relação

- Val atualN é o novo valor do último atributo na relação

Para uma inserção, a informação valor anterior conterá o valor nil. Para uma remoção, a informação valor atual conterá o valor nil.

Na tabela 3 é mostrado um exemplo de log.

\begin{tabular}{|l|l|l|l|}
\hline Fonte1 & Rel1 & Atrib1, nil, 30, .. AtribN, nil, 20 & inserção \\
Fonte2 & Rel1 & Atrib1, nil, 55, .. A.AtribN, nil, 32 & \\
Fonte1 & Rel2 & Atrib1, 75, nil, .. ,AtribN, 50, nill & remoção \\
Fonte1 & Rel1 & Atrib1, 30, nil, .. ,AtribN, 20, nil & alteração \\
Fonte1 & Rel1 & Atrib1, nil, 37, .. ,AtribN, nil, 20 & alteração \\
\hline
\end{tabular}

Tabela 3: Exemplo de arquivo de log.

Dessa forma cada log local de um wrapper pode ser expresso como:

$$
\cup t_{i}
$$

onde:

$t_{i}$ são todas as transações confirmadas que acontecem na fonte $i$.

\subsubsection{Estrutura de-para do algoritmo de log de nível zero}

Após as informações serem gravadas no log local dos wrappers, o wrapper irá determinar quais são as informações relevantes que serão transferidas para o data warehouse.

Adotando a definição de [SBCL00], informações relevantes são aquelas que fazem parte da visão do warehouse. Para determiná-las existe uma estrutura de-para, ou seja, uma relação que mapeia o uso das relações das fontes de dados no data warehouse. Esta relação é mostrada na tabela 4.

\begin{tabular}{|l|l|l|l|l|l|}
\hline Fonte & Rel Fonte & Rel DW & Prior & Atrib na Fonte & Atrib no DW \\
\hline
\end{tabular}

Tabela 4: Forma geral da tabela de-para.

em que : 
1. A primeira coluna indica a fonte de dados.

2. A segunda coluna indica o nome da tabela na fonte.

3. A terceira coluna indica o nome da tabela no data warehouse.

4. A quarta coluna indica a prioridade de atualização dessa relação.

5. A quinta coluna é um ponteiro para a lista de atributos da relação fonte que são necessários para o data warehouse.

6. A sexta coluna é um ponteiro para os nomes dos atributos no data warehouse correspondentes aos atributos da relação fonte.

A prioridade dada a cada fonte de dado, depende da porção de dados do warehouse que necessita de maior atualização. Dessa maneira, podemos estabelecer uma ordem entre as atualizações vindas de uma mesma fonte e entre fontes de dados. Quanto maior a prioridade dada a uma relação de uma determinada fonte, mais rápido sua informação será passada para o data warehouse, quanto menor a prioridade, mais devagar será sua atualização no data warehouse. Um exemplo da relação de-para é mostrado na tabela 5. Considere que as relações compra e venda estão em fontes diferentes e fornecedor e venda estão na mesma fonte mostradas na tabela 5

\begin{tabular}{|l|l|l|l|l|l|}
\hline Fonte & Rel Fonte & Rel DW & Prior & Atrib na Fonte & Atrib no DW \\
\hline F1 & Venda & Venda & 2 & cliente, valor, item & cliente, valor, item \\
F2 & Compra & Compra & 1 & fornecedor, valor, item & fornecedor, valor, item \\
F1 & Fornecedor & Fornecedor & 1 & fornecedor, nome, end, telefone & fornecedor, nome, end, telefone \\
\hline
\end{tabular}

Tabela 5: Exemplo de relação de-para.

Com o uso da relação de-para o wrapper monta um log de saída para cada fonte de dados que contém apenas as informações relevantes para o data warehouse e suas prioridades. Nesse log de saída temos o nome da relação no data warehouse, a lista de atributos a ser atualizada, cada um com seu valor anterior, valor atual e prioridade. Um exemplo de log de saída é mostrado na tabela 6:

Cada log de saída de um wrapper pode ser expresso como: 
\begin{tabular}{l|l} 
Rel DW & Atrib1 DW, Val ant1, Val atual1, Prior1, ... AtribN DW, Val antN, Val atualN, PriorN \\
\hline
\end{tabular}

Tabela 6: Formato do log de saída.

$$
\cup t_{i}-U t d_{i}
$$

em que:

$t_{i}$ são todas as transações confirmadas que acontecem na fonte $i$;

$t d_{i}$ são todas as transações descartadas da fonte $i$,ou seja as que não são relevantes para o data warehouse;

\subsubsection{Módulo de Carga}

Para transferir um dado para o warehouse existe um escalonador de carga responsável pela leitura do log saída de cada wrapper. Esse escalonador varrerá os logs de acordo com uma ordem determinada pelo usuário. Essa ordem pode ser determinada por um parâmetro de carga de dois tipos:

- A primeira maneira considera que cada log de saída pertence a uma fonte, e estes são identificados univocamente. Dessa forma pode-se determinar a ordem de leitura de cada um deles. Essa ordem de leitura reforça a prioridade na leitura de informações, pois as partes que necessitarem ser mais constantemente atualizadas terão os logs de saída correspondentes com prioridade maior em relação aos demais. Além disso, quando um $\log$ é elencado para leitura, serão respeitados dois parâmetros para a leitura do mesmo: o número de linhas a serem lidas no log; a prioridade de cada atualização. Primeiro o algoritmo determina o número de linhas que serão lidas em cada log por meio do parâmetro l. Dentre esse número de linhas, as com maior prioridade serão repassadas primeiro ao data warehouse. Após a leitura das $l$ linhas, este ponto é marcado criando um checkpoint (ponto de checagem). Esse ponto de checagem será mantido até que as próximas linhas sejam consultadas e estas contidas até o ponto de checagem descartadas.

- A segunda maneira consiste em ler todos os logs até o número $l$ de linhas e então repassar primeiro para o warehouse todas as transações que têm maior prioridade. Essa leitura pode ser feita através de um algoritmo de ordenação externa que primeiro considera as atualizações com maior prioridade. Nessa técnica, as prioridades atribuídas na estrutura 
de-para têm um ajuste de menor granularidade, pois falamos agora de um escalonamento global entre transações de fontes diferentes, não entre estruturas de log.

Para determinar as porções de dados que devem ser atualizadas e a freqüência dessa utilização, pode-se usar o método desenvolvido em [Ita02]. Nesse trabalho, a definição das porções dinâmicas e estáticas do data warehouse deve ser iniciada com a análise das características do ambiente operacional, visando a carga do data warehouse.

O ambiente operacional a ser analisado é o conjunto de funções que gera as informações que serão armazenadas nas porções supramencionadas. Para que essa avaliação seja feita, é necessário dividir as aplicações transacionais em conjuntos de funções que manipulam uma parte dos dados. Essa parte, ou subconjunto dos dados, deve ser considerada como uma unidade funcional dentro do ambiente operacional. Cada uma dessas unidades funcionais pode ter comportamentos distintos no que se refere às necessidades de atualizações.

\subsubsection{Data Warehouse}

O data warehouse será atualizado pelo módulo de carga. A estrutura de armazenamento do data warehouse é diferente das estruturas convencionalmente usadas. No modelo proposto para armazenamento do warehouse temos as informações das fontes representadas num primeiro nível de relacionamento semântico entre elas que nominamos de modelo semântico de nível zero. Nesse modelo, que é uma alteração do modelo estrela ${ }^{23}$, as informações estão representadas de acordo com a correlação semântica existente nas fontes de dados, ou seja, as informações estarão representadas sem nenhum nível de agregação no data warehouse. Com esse modelo, a atualização do data warehouse ficará simplificada, pois como não temos agregação, o módulo de carga terá apenas que repassar as informações lidas para o data warehouse. Um exemplo dessa estrutura é mostrado na figura 10:

\footnotetext{
${ }^{23}$ Nesse texto modelo estrela será usado como um termo equivalente ao star schema.cujos detalhes podem ser encontrados em [KRRT98]
} 


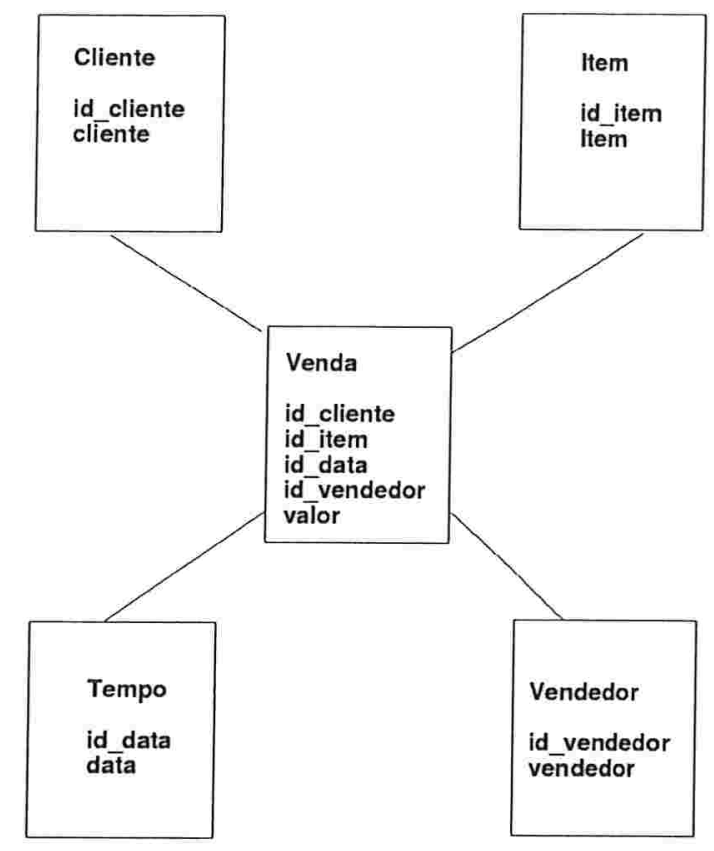

Figura 10: Modelo de Data Warehouse de nível zero

Com esse armazamento, criar visões para análises dos dados torna-se mais fácil, dado que as informações estão armazenadas no data warehouse e, principalmente, pelo nível de agregação zero. Esse tipo de armazenamento permite mudanças das visões e a criação de novas visões sem acesso às fontes de dados, bem como uma análise mais detalhada do negócio, por causa da riqueza de informações representadas.

Um modelo da nova arquitetura para atualizações de dados para data warehouse é mostrado na figura 11 


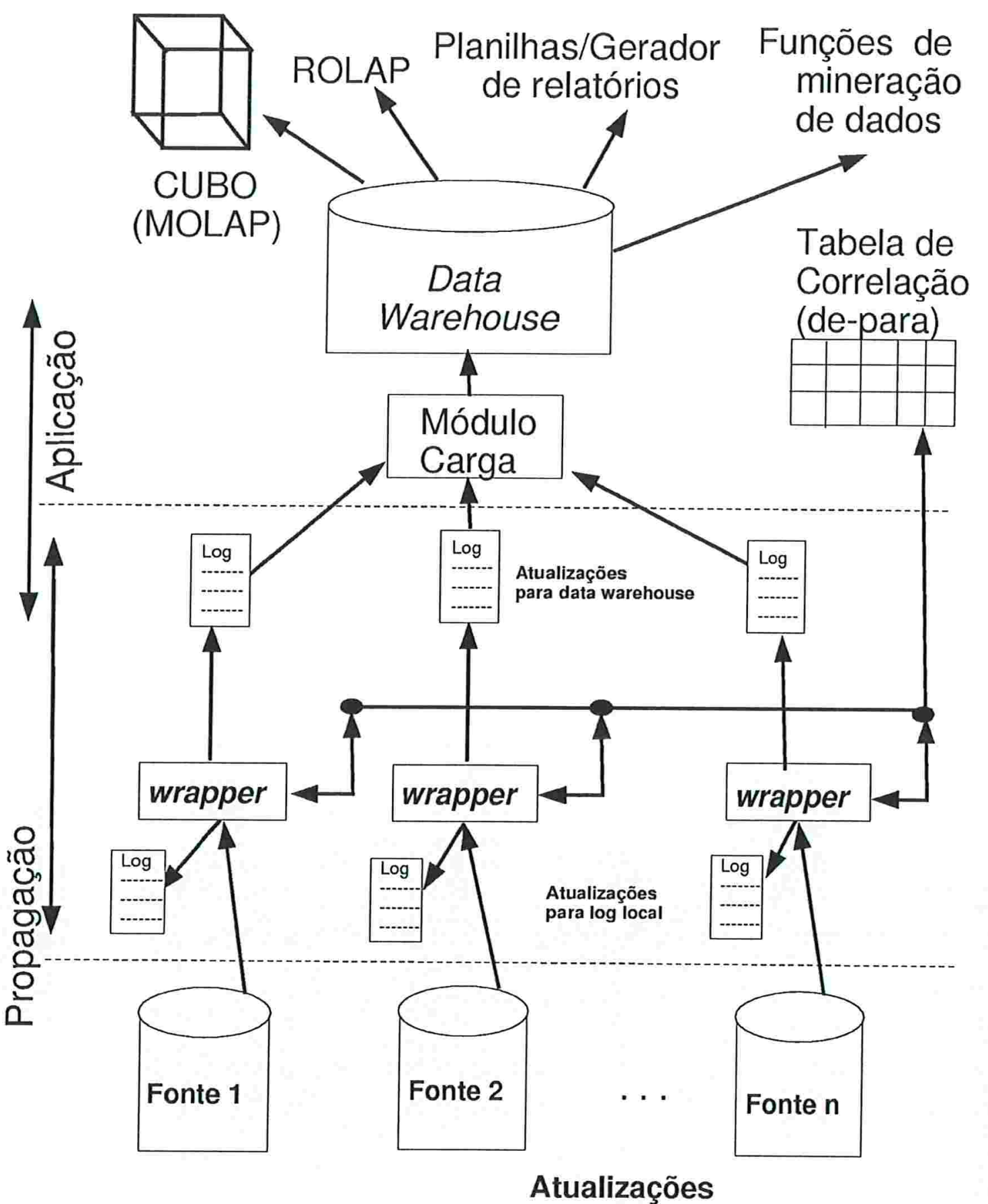

Figura 11: Arquitetura para atualizações de dados de data warehouse no modelo semântico de nível zero 


\subsubsection{Algoritmo de propagação para wrapper}

\section{Definições:}

- Seja $A_{i}$ uma atualização confirmada em uma fonte $i$.

- Sejam $L_{i}$ e $L s_{i}$ os logs local e de saída de uma fonte $i$.

- Seja $T d p$ a tabela depara que contém o mapeamento dos atributos das relações nas fontes no data warehouse.

- Seja $A_{i}^{\prime}$ a atualização que é gravada no $\log$ de saída $L s_{i}$ após a escolha dos atributos relevantes de $A_{i}$ consultando $T d p$.

- Seja checkpoint a marca colocada em cada log, indicando que as informações até esta posição já foram lidas e aplicadas.

\section{Em cada fonte:}

Após confirmar a atualização $A_{i}$ envie $A_{i}$ para o wrapper

\section{No wrapper}

Inicializa $L_{i}$ e $L s_{i}$ como $\emptyset$

Quando receber uma atualização $A_{i}$ da fonte $i$

Escreva $A_{i}$ em $L_{i}$

$\forall A_{i} \in L_{i}$ faça

Se $\exists$ checkpoint

limpe $L_{i}$ até checkpoint

Se $\exists$ atributos $A_{i} \in T d p$

monte $A_{i}^{\prime}$ com esses atributos

escreva $A_{i}^{\prime}$ em $L s_{i}$

A cada escrita $A_{i}^{\prime}$ em $L s_{i}$

Escreva checkpoint $L_{i}$ 


\subsubsection{Algoritmo módulo de carga para data warehouse}

\section{Definições:}

- Seja parametro_carga o parâmetro que determina o método de carga que será utilizado. Inicialmente, esse parâmetro alternará entre uma sequência de ordenação de logs e interpolação dos logs

- insira_ $D W$ é uma função que pega uma determinada linha de $L s_{i}$ e aplica esta linha ao data warehouse

- Ordena $\left(L s_{i}, l, \operatorname{logaux}\right)$ é uma função que recebe o $\log$ de saída de cada fonte $i$ e faz a ordenação desse log em uma estrutura auxiliar chamada logaux. O número de linhas a serem ordenadas dependerá do parâmetro passado em $l$.

- Ordena_Externo $\left(L s_{i} \ldots L s_{n}, l\right.$, logaux) é uma função que recebe todos os logs das fontes e faz uma ordenação externa desses logs (interpolação) em uma estrutura auxiliar chamada logaux. O número de linhas a serem ordenadas em cada log dependerá do parâmetro passado em $l$. Essa ordenação externa pode ser feita com algoritmos como o descrito em [RG00].

\section{Em cada fonte:}

Se parametro_carga $=$ metodo1

Para $\mathrm{i}$ de 1 ate $\mathrm{n}_{-} \log$ faça

$$
\begin{aligned}
& \text { Ordena }\left(\mathrm{Ls}_{i}, 1, \text { logaux }\right) \\
& \text { Para j de } 1 \text { ate } 1 \text { faca } \\
& \text { insira_DW(logaux,j) } \\
& \text { escreva checkpoint(logaux) }
\end{aligned}
$$

Senao

Se parametro_carga $=$ metodo2

Ordena_Externo $\left(\mathrm{Ls}_{i}, \ldots, \mathrm{Ls}_{n}, 1\right.$, logaux $)$

Para $\mathbf{j}$ de 1 ate tamanho(logaux) faca

insira_DW $(\operatorname{logaux}, \mathrm{j})$

escreva checkpoint(logaux) 


\section{Conclusão}

Com o estudo realizado nos capítulos anteriores, pode-se dividir a atualização de data warehouse atualmente em três classes: atualização estática, atualização síncrona e atualização assíncrona. $\mathrm{Na}$ atualização estática as mudanças nas fontes são passadas em um arquivo de lote para o warehouse em uma certa janela de tempo fixa determinada pelo usuário, sendo esta solução a mais utilizada comercialmente.

Na atualização síncrona [ZGMHW95, ZGMW98, AASY97, JCR02], a maioria das soluções engloba a atualização de dados e algumas atualizações de dados e de esquemas de dados das fontes. $\mathrm{Na}$ atualização síncrona, cada transação que é confirmada no sistema transacional, é imediatamente passada para o data warehouse, que deve ser atualizado de acordo com as informações necessárias às suas visões materializadas. Nessa classe de algoritmos, o principal problema a ser evitado são as transações interferentes que podem gerar inconsistência nos dados para data warehouse .

$\mathrm{Na}$ atualização assíncrona [SBCL00], que é a classe intermediária entre a atualização síncrona e estática, tem-se que grande parte das soluções engloba atualização de dados. Nessa classe de algoritmos quando uma transação de atualização é gerada, esta é tratada por alguma camada intermediária de modo que se faça a atualização nas visões do data warehouse e, principalmente, evite ou minimize $o$ acesso às fontes transacionais para buscar as informações necessárias à atualização das visões materializadas do data warehouse.

Nos dias atuais, com um mercado cada vez mais globalizado, nota-se que existem partes dos data warehouses que necessitam estar mais freqüentemente atualizados que outras porções. Para essas porções de dados nos warehouses pode-se adotar uma carga síncrona ou assíncrona. Se for adotada uma carga síncrona, será necessário absorver os custos de uma atualização síncrona, ou seja, as transações trocadas entre as fontes de dados e o data warehouse para consistência das visões, e a concorrência gerada por essas transações nos dois ambientes que muitas vezes poderá tornar os ambientes lentos para utilização.

Dentre as soluções síncronas, a solução proposta por [JCR02] cria relações em cada wrapper e armazena as atualizações ocorridas nas fontes, dessa maneira, quando as visões do data warehouse precisam ser atualizadas, o warehouse consulta as relações nos wrappers. Porém, uma grande desvantagem dessa solução é o espaço de armazenamento para todas as atulizações(transações) em cada wrapper de fonte. Dessa forma, a solução assíncrona, em muitos casos pode ser a melhor 
a ser adotada, pois ela não terá uma janela fixa para ocorrer e poderá ser executada quando o sistema estiver com características propícias para suportá-la, não necessariamente quando a atualização ocorre nas fontes de dados. Com todos os estudos feitos, foi desenvolvida a proposta de um novo algoritmo assícrono baseado na solução proposta por [SBCL00] para atualizações de data warehouse. Foi escolhida a característica assíncrona, porque nem todos os dados precisam estar atualizados em tempo real.

\subsection{Comparação entre algoritmos assíncronos}

Nesta seção será feita uma comparação entre a soluçao apresentada por [SBCL00] e a apresentada nesta dissertação de mestrado.

\subsubsection{Fontes de dados}

Nos dois algoritmos as fontes bases de dados são consideradas como sendo relacionais e podem estar em diversos sítios diferentes. Pressupõe-se que não existe comunicação entre as fontes.

\subsubsection{Extração das atualizações de dados}

Todas as mudanças ocorridas nas fontes de dados são armazenadas nos logs locais de cada SGBD. No algoritmo de propagação de rolagem as atualizações para o warehouse são lidas a partir desse log e são extraídas apenas as mudanças relevantes às visões. Essas atualizações são armazenadas em uma tabela para cada fonte de dados. No algoritmo de log, as atualizações confirmadas são repassadas para os wrappers por triggers nas relações e são totalmente armazenadas em um log local em cada wrapper.

\subsubsection{Atualização Incremental para warehouse}

Para atualizar o warehouse, o algoritmo de Propagação de Rolagem coloca os incrementos às visões materializadas em uma relação intermediária chamada de visão delta, que conhece as visões do warehouse. Dessa maneira, quando as informações de uma determinada fonte de dados são enviadas à visão delta, esta pode ter que consultar todas as fontes de dados para montar o incremento à visão, e por causa desse processo pode ter que tratar as atualizações concorrentes. No algoritmo de log quando uma atualização é passada do log local do wrapper para o log de saida, um filtro será aplicado por meio da estrutura de-para para determinar quais informações 
são realmente relevantes para o warehouse. Desta forma no log de saída temos apenas informações para o warehouse. Um fator de grande importância é que para montar o log de saída, o wrapper não precisa consultar as fontes de dados, já que toda a informação que ele necessita está na estrutura de-para.

\subsubsection{Aplicação das atualizações incrementais para warehouse}

Os dois algoritmos apenas repassam incrementalmente as atualizações para o warehouse. A grande diferença entre eles é que o algoritmo de propagação de rolagem teve que gerar consultas de compensação para chegar ao resultado, enquanto o algoritmo de log simplesmente repassou a informação filtrada que chegou ao log de saida. Dessa maneira, no algoritmo de log quando uma atualização é confirmada e repassada, ela pode ser passada para o warehouse, desde que seja relevante, sem precisar de novas consultas às fontes de dados, não gerando concorrência local de dados nem atraso para gerar as informações complementares.

\subsubsection{Visões}

Ao contrário de todos os algoritmos descritos, nossa solução trabalha com a proposta de visões dinâmicas. Todos os demais algoritmos, por tratarem visões materializadas, se preocupam em incrementá-las , e, se for necessária a criação de novas visões, as fontes terão que ser consultadas. Em nossa solução, quando for necessária uma nova visão, os dados já estarão disponíveis no warehouse. Dessa maneira, transferimos a criação da visão para as ferramentas que utilizam o data warehouse (cubos, planilhas eletrônicas, etc) dando assim maior mobilidade para as consultas. Para se manter uma boa estrutura de nível zero, é necessária uma análise do modelo de negócios da empresa que utiliza o data warehouse. Isto se deve ao fato de que para podermos variar as consultas e, principalmente, para que não se retorne às fontes base, as informações devem estar representadas no warehouse. Por esse motivo, o processo de análise para a construção do data warehouse pode ser um pouco mais demorado que a definição de visões materializadas para as consultas mais comuns, já que exigirá um maior conhecimento da área de atuação do negócio. Transferir o processo de criação das visões para as ferramentas que utilizam os dados do warehouse não significa tornar o processo de consulta às visões mais demorado. Já existem

algumas ferramentas no mercado que fazem atualização incremental das visões construídas a partir dos dados do data warehouse como ferramentas de MOLAP (cubos). 


\subsection{Dificuldades Encontradas}

As dificuldades encontradas concentraram-se principalmente na compreensão dos algoritmos de atualizações de dados para o data warehouse devido sua complexidade para os processos de compensação e transferência dos dados.

\subsection{Trabalhos futuros}

Com a definição do algoritmo assíncrono, deseja-se implementá-lo e testar seu desempenho, fazendo comparações com os demais algoritmos, por meio de um ambiente transacional que permita simulações.

É possível fazer uma extensão do algoritmo para que se possa controlar, não só atualizações de dados para o data warehouse, mas também atualizações de esquemas das fontes de dados. 


\section{Referências}

[AASY97] D. Agrawal, A. El Abbadi, A. Singh, and T. Yurek. Efficient view maintenance at data warehouses. In Proceedings of the ACM SIGMOD International Conference on Management of Data, volume 26,2 of SIGMOD Record, pages 417-427, New York, May 13-15 1997. ACM Press.

[AS89] D. Agrawal and S. Sengupta. Modular synchronization in multiversion databases: version control and concurrency control. In James Clifford, Bruce Lindsay, and David Maier, editors, Proceedings of the 1989 ACM SIGMOD international conference on the management of data, Portland, Oregon, May 31-June 2, 1989, pages 408-417, New York, NY 10036, USA, 1989. ACM Press.

[AV98] Christopher Adamson and Michael Venerable. Data Warehouse Design Solutions. John Wiley \& Sons, 1998.

[BGMS92] Yuri Breitbart, Hector Garcia-Molina, and Abraham Silberschatz. Overview of multidatabase transaction management. VLDB Journal: Very Large Data Bases, 1(2):181-293, 1992.

[BHG87] P. Bernstein, V. Hadzilacos, and N. Goodman. Concurrency Control and Recovery in Database Systems. Addison-Wesley, 1987. http://research.microsoft.com/pubs/ccontrol/.

[BLT86] J. A. Blakeley, P.-A. Larson, and F. W. Tompa. Efficiently updating materialized views. In C. Zaniolo, editor, SIGMOD, pages 61-71, Washington, DC, May 1986. ACM.

[CCZR01] Songting Chen, Jun Chen, Xin Zhang, and Elke A. Rundensteiner. Detection and correction of conflicting concurrent data warehouse updates. Technical report, Worcester Polytechnic Institute, 2001.

$\left[\mathrm{CGL}^{+}\right.$96] Latha S. Colby, Timothy Griffin, Leonid Libkin, Inderpal Singh Mumick, and Howard Trickey. Algorithms for deferred view maintenance. In SIGMOD'9\%, pages 469-480, 1996.

[GM95] Ashish Gupta and Inderpal Singh Mumick. Maintenance of Materialized Views: Problems, Techniques and Applications. IEEE Quarterly Bulletin on Data Engi- 
neering; Special Issue on Materialized Views and Data Warehousing, 18(2):3-18, 1995.

[GMS] Ashish Gupta, Inderpal Singh Mumick, and V.S Subrahmanian. Maintaining views incrementally (extended abstract).

[HZ96a] Richard Hull and Gang Zhou. A framework for supporting data integration using the materialized and virtual approaches. SIGMOD Record (ACM Special Interest Group on Management of Data), 25(2):481, 1996.

[HZ96b] Richard Hull and Gang Zhou. Towards the study of performance trade-offs between materialized and virtual integrated views. In VIEWS, pages 91-102, 1996.

[Ita02] Isabel Italiano. Classificação dos domínios transacionais e analíticos para avaliação de alternativas de sincronismo em projetos de data warehouse. Master's thesis, Instituto de Matemática e Estatística - Universidade de São Paulo. Junho, 2002.

[JCR02] Chen Jun, Songting Chen, and Elke A. Rundensteiner. A transactional model for data warehouse maintenance. In ER'2002, Tempere, Finland, september 2002.

[KRRT98] Ralph Kimball, Margy Ross, Laura Reeves, and Warren ThornWaiten. Data Warehouse Lifecycle Toolkit, the expert methods for designing, developing, and deployind Data Warehouses. John Wiley Professional, 1998.

[LCR02] Bin Liu, Songting Chen, and Elke A. Rundensteiner. Batch data warehouse maintenance in dynamic environment. In Proceedings of CIKM' 2002, Nov, McLean VA, 2002.

[MSRK98] Mukesh K. Mohania, Sunil Samtani, John Roddick, and Yahiko Kambayashi. Advances and research directions in data warehousing technology, 1998.

[QGMW96] Dallan Quass, Ashish Gupta, Inderpal Singh Mumick, and Jennifer Widom. Making views self-maintainable for data warehousing. In Fourth International Conference on Parallel and Distributed Information Systems (PDIS '96), pages 158-169, Los Alamitos, Ca., USA, December 1996. IEEE Computer Society Press.

[QW97] Dallan Quass and Jennifer Widom. On-line warehouse view maintenance for batch updates. In Proceedings of the ACM SIGMOD International Conference on Ma- 
nagement of Data, volume 26,2 of SIGMOD Record, pages 393-404, New York, May 13-15 1997. ACM Press.

[RG00] Raghu Ramakrishnan and Johannes Gehrke. Database Management Systems, chapter 11. Mc Graw-Hill, 2000.

[SBCL00] Kenneth Salem, Kevin S. Beyer, Roberta Cochrane, and Bruce G. Lindsay. How to roll a join: Asynchronous incremental view maintenance. In Weidong Chen, Jeffrey F. Naughton, and Philip A. Bernstein, editors, Proceedings of the 2000 ACM SIGMOD International -Conference on Management of Data, volume 29, pages 129-140. ACM, 2000.

[SMKK99] Sunil Samtani, Mukesh K. Mohania, Vijay Kumar, and Yahiko Kambayashi. Recent advances and research problems in data warehousing. Lecture Notes in Computer Science, 1552:81-92, 1999.

[ZGM98] Yue Zhuge and Hector Garcia-Molina. Performance Analysis of WHIPS Incremental Maintenance. Technical report, University of California, Santa Barbara. Computer Science., 1998.

[ZGMHW95] Yue Zhuge, Hector Garcia-Molina, Joachim Hammer, and Jennifer Widom. View maintenance in a warehousing environment. In Michael J. Carey and Donovan A. Schneider, editors, Proceedings of the 1995 ACM SIGMOD International Conference on Management of Data, pages 316-327, San Jose, California, 22-25 May 1995.

[ZGMW96] Yue Zhuge, Hector Garcia-Molina, and Janet L. Wiener. The strobe algorithms for multi-source warehouse consistency. In Fourth International Conference on Parallel and Distributed Information Systems (PDIS '96), pages 146-157, Los Alamitos, Ca., USA, December 1996. IEEE Computer Society Press.

[ZGMW98] Yue Zhuge, Hector Garcia-Molina, and Janet L. Wiener. Consistency Algorithms for Multi-Source Warehouse View Maintenance. Distributed and Parallel Databases, 6(1):7-40, 1998. 
[ZR02] Xin Zhang and Elke A. Rundensteiner. Integrating the maintenance and synchronization of data warehouses using a cooperative framework. Information Systems Journal, 4(27):219-243, 2002. 